\title{
Relative polyphagy of "Mediterranean" cryptic Bemisia tabaci whitefly species and global pest status implications
}

\author{
Soňa Vyskočilová ${ }^{1}$ (D) Susan Seal ${ }^{1}$ D J John Colvin $^{1}$ (D)
}

Received: 25 August 2018 / Revised: 14 February 2019 / Accepted: 6 April 2019 / Published online: 16 April 2019

(c) The Author(s) 2019

\begin{abstract}
The Bemisia tabaci whitefly was previously considered a single, highly polyphagous species, but is now accepted as a group of cryptic biological species. We investigated the host plant relations of two sister species, the "Mediterranean" (MED) composed of the Q1 and Q2 mitochondrial groups and the "ASL" species (formerly considered a MED group), to discover whether polyphagy was related to the global pest status. We compared their performance by measuring the oviposition rate, survival, fecundity and proportion of female offspring on 13 host plants from nine families. In addition, oviposition preference was compared among leaves of different ages. Significant $(P<0.05)$ differences were found between populations in all parameters, particularly in adult survival and fecundity. Females preferred strongly to oviposit on the oldest true leaf on tobacco and tomato and on young leaves of sweet potato and pepper. The greatest differences in fecundity occurred on bean, okra, squash, pepper and tobacco. Hosts favourable for all four populations were cotton and sweet potato; no offspring were produced on cassava, chard or tomato. Host ranges of Q1 populations from Europe and sub-Saharan Africa differed despite their close genetic relatedness at the mitogenome level. Discrepancies between the parental and offspring fitness were observed. Our findings show that (1) the species have differing but overlapping host plant ranges and (2) the Q1 is the most polyphagous and can utilise tobacco, which predisposes it to evolving resistance to neonicotinoids. Our findings contribute to the understanding of ecology of this pest species complex and aid the development of efficient pest control strategies.
\end{abstract}

Keywords Mitochondrial phylogenetic groups $\cdot$ Invasiveness $\cdot$ Survival analysis · Optimal oviposition theory $\cdot$ Optimal foraging theory $\cdot$ Bacterial endosymbionts

\section{Key message}

- The "Mediterranean" (MED) putative species of the Bemisia tabaci complex is a globally invasive pest and plant virus vector.

- MED was recently discovered to comprise more than one cryptic B. tabaci species. Groups Q1 and Q2 form one species, while African silver-leafing (ASL) is a different species.

Communicated by A. R. Horowitz.

Electronic supplementary material The online version of this article (https://doi.org/10.1007/s10340-019-01113-9) contains supplementary material, which is available to authorized users.

Soňa Vyskočilová

s.vyskocilova@gmail.com

1 Natural Resources Institute, University of Greenwich, Central Avenue, Chatham Maritime, Kent ME4 4TB, UK
- Host plant range differences between these cryptic species, and how this may affect their relative pest status, remained unknown.

- We found significant differences in host use between these sister species, which has implications for their control.

\section{Introduction}

Whiteflies classified as Bemisia tabaci (Gennadius) (Hemiptera: Aleyrodidae) are phloem-feeding pests damaging food and fibre crops and ornamental plants through direct feeding, deposition of honeydew and virus transmission (Seal et al. 2006; De Barro et al. 2011). B. tabaci are distributed globally, from tropical to temperate climates and across all continents except Antarctica (Oliveira et al. 2001). Evidence collected from phylogenetic analyses based on partial mitochondrial cytochrome oxidase I (mtCOI) gene sequences, 
coupled with reciprocal mating experiments, provided the first evidence that, rather than being a single biological species, B. tabaci is a group of cryptic species (Frohlich et al. 1999; Colvin et al. 2004; Maruthi et al. 2004; Dinsdale et al. 2010; Xu et al. 2010; Boykin et al. 2012).

To design efficient and sustainable management strategies to control an insect vector and the viruses it transmits, it is important to understand its ecology. In the field, many of the interactions between whitefly species, and also with their predators, symbionts and pathogens, can be affected by the plant host (Inbar and Gerling 2008). Whiteflies suck phloem from their hosts by inserting their stylet between leaf cells and into the phloem sieve elements (Fürstenberg-Hägg et al. 2013). Upon the initial probing into the leaf epidermis, the phloem-feeder determines the suitability of the host by detecting the nutritional content and encountering the plant chemical defences (Powell et al. 2006; Walling 2008). These defences can be constitutive and/or induced by the inflicted feeding damage, and they may influence the settling, feeding, oviposition, growth and development, fecundity, and/ or fertility of the herbivore insect (Baldwin and Preston 1999; Walling 2000; Elsayed 2011). The suitability of each plant then shapes the range of hosts suitable for feeding and reproduction of the pest. Such knowledge helps make predictions about its population dynamics in the field and so is particularly important for invasive pests, such as the "Middle East-Asia Minor 1" (MEAM1) and "Mediterranean" (MED) putative species within the $B$. tabaci complex. However, specific and accurate information about host range of individual species within the $B$. tabaci complex is limited.

Until the early 1990s, B. tabaci (sensu Russell 1957) was considered to be a single polyphagous species with 506 plant species listed as hosts (Mound and Halsey 1978; Greathead 1986). As early as in the 1950s, however, the scientific community distinguished between different host-associated races within B. tabaci. In Puerto Rico, for example, one B. tabaci race was strongly associated with Jatropha gossypifolia and transmitted the Jatropha mosaic virus exclusively to and from J. gossypifolia (Bird 1957), while the other race was widely polyphagous and transmitted various geminiviruses to and from numerous hosts (Bird and Maramorosch 1978). A similar phenomenon was observed in Côte d'Ivoire, where one B. tabaci race specialised on cassava and eggplant, while the other fed on multiple plant species excluding cassava (Burban et al. 1992). Various host-specialised populations were called host races (e.g. Jatropha and Sida race), strains (e.g. poinsettia strain) or biotypes (e.g. okra and cassava biotype) (Bird and Maramorosch 1978; Perring et al. 1992; Omondi et al. 2005). Most other biotypes were described on the basis of esterase banding patterns (Costa and Brown 1991; Bedford et al. 1992). After the more widespread use of DNA sequence data and acceptance that B. tabaci (sensu Russell 1957) is a complex of cryptic species, the biotypes and host races were synonymised into phylogenetic groups based on their 3' partial mtCOI sequences, with an associated naming system for putative cryptic species (Dinsdale et al. 2010; De Barro et al. 2011; Liu et al. 2012b). The Q, J, $\mathrm{L}$ and ASL B. tabaci biotypes were synonymised into MED putative species.

Since the recognition and assignment of B. tabaci populations into different species within the complex, knowledge on the host range of individual species remained to be reassessed. The MEAM1 species (formerly B and B2 biotypes) received the most attention as it was the first globally invasive species from the $B$. tabaci complex (Toscano et al. 1998). However, MED became a globally invasive species shortly after MEAM1, which prompted the scientific community to investigate the host use by MED as well, often in comparison with MEAM1. It was found that both species performed similarly well on tomato, cucumber and aubergine, although some discrepancies occurred between studies (Jiang et al. 1999; Iida et al. 2009; Liu et al. 2012a; Jiao et al. 2012). Cabbage was unequivocally more suitable for MEAM1 (Iida et al. 2009; Liu et al. 2012a; Jiao et al. 2013), while poinsettia, cotton, pepper and bean were more favourable for MED (Muñiz and Nombela 2001; Iida et al. 2009; Liu et al. 2012a; Chu et al. 2012; Jiao et al. 2012, 2013). However, these differences can be specific to plant cultivars, as MEAM1 outperformed MED on the "Piquillo" cultivar of pepper (Muñiz and Nombela 1997).

The more recent invader, MED, has been split into four groups based on its intraspecies genetic variability and geographic range: Q1, Q2, Q3 and African silver-leafing (ASL, referring to the silver-leafing symptoms caused by feeding on squash) (Gueguen et al. 2010). Given these intraspecies differences, the status of MED as a single species has recently been reassessed (Mouton et al. 2015; Vyskočilová et al. 2018). Microsatellite DNA marker analysis of sympatric field populations (Mouton et al. 2015) and laboratory crossing experiments (Vyskočilová et al. 2018) showed that the ASL group is isolated reproductively from Q1 and Q2. In addition, despite its name, there is no published evidence of the capacity of ASL populations to induce silver-leafing symptoms in squash (Vyskočilová et al. 2018). The reproductive incompatibility between ASL and MED populations and their genetic distinctness led to the conclusion that ASL belongs to a non-MED species (Vyskočilová et al. 2018). Until this species is assigned a new binomial name, we refer to it as "ASL".

There are some reports indicating host plant range differences among MED groups and "ASL". In a field survey in Uganda, the Q1 (referred to as "Ug5") was only collected from Nicotiana tabacum, while the "ASL" (referred to as "Ug4") occurred on Cucumis sativus, Cucurbita pepo, Solanum melongena, Leonotis nepetifolia and Pavonia urens (Sseruwagi et al. 2005). Different 
host preferences were also reported for MED populations Q1 and Q2 in Italy, where individuals from Q2 were more predominant on solanaceous hosts, while Q1 adults were collected from members of Convolvulaceae, Malvaceae and Asteraceae (Parrella et al. 2014). The surveys above, however, only analysed adult whiteflies collected in the field, and it remained uncertain whether the different populations were able to develop and complete a full life cycle on the plant species from which the adults were collected.

The aim of this study, therefore, was to find out whether the different MED groups and "ASL" species share the same host plant range or whether they specialise on different host plants. We used no-choice laboratory experiments to test specifically whether or not the different populations could complete a reproductive cycle on a range of 13 plants from nine families. These plants included recognised hosts of MED and/or "ASL", as well as novel encounters to broaden our knowledge about the host range of this invasive pest. Similar to other published studies (e.g. Xu et al. 2011; Alon et al. 2013; Su et al. 2015; Pappas et al. 2018; Mugerwa et al. 2019), we quantified the oviposition rate, longevity and fertility of the adults to measure the whitefly performance on each host. In addition, we recorded the proportion of female offspring to observe a potential relationship between the rate of egg fertilisation and the host plant suitability. These data are coupled with information about the infection status of the experimental populations by six common bacterial endosymbionts that can affect insect reproduction (Werren et al. 2008; Duron et al. 2008) and fitness (Oliver et al. 2003; Himler et al. 2011), as well as genetic distances between the experimental populations measured in mitochondrial DNA acquired by high-throughput sequencing. These additional data shall facilitate linking future studies to this one.

\section{Materials and methods}

\section{Growing plants and rearing insects}

Plants were grown in a whitefly-free room at $28 \pm 2{ }^{\circ} \mathrm{C}$, $50-60 \%$ relative humidity and a 14:10 light:dark photoperiod. Plant species used for the host plant performance bioassays are listed in Table 1. After plantlets rooted in loambased compost (J. Arthur Bower's John Innes No. 2) reached $10-15 \mathrm{~cm}$ above soil level, they were individually enclosed in Lock\&Lock whitefly-proof cages (Wang et al. 2011) with two additional side openings in the upper container covered by $160-\mu \mathrm{m}$ nylon mesh. The plants were watered twice a week.

Colonies of the whitefly Bemisia tabaci (Table 2) were reared on aubergine plants (S. melongena "Black Beauty") in rectangular $45 \times 44 \times 44 \mathrm{~cm}$ cages (BugDorm, US) at $28 \pm 2{ }^{\circ} \mathrm{C}, 30 \%$ relative humidity and $14: 10$ light:dark photoperiod.

\section{Photographs of abaxial leaf surfaces}

A separate set of plants was grown as described above, to photograph leaf surfaces. Detached leaves in different growth stages were placed under a stereomicroscope (Nikon SMZ18) with an attached DSLR camera (Nikon D5300) and illuminated with an LED light source (Photonic Optics F3000). Photographs were taken with automatic camera settings at 20x magnification (Fig. S1 in Online Resource 1).

\section{Whitefly species identification and endosymbiont screening}

Species identity of the whitefly populations was tested by sequencing the $3^{\prime}$ partial sequence of the mtCOI gene
Table 1 Plants used in the study with the information on the variety, taxonomic family and propagation method

\begin{tabular}{lllll}
\hline Host name & Plant species & Variety & Family & Propagation \\
\hline Aubergine & Solanum melongena & Black Beauty & Solanaceae & Seeds \\
Bean & Phaseolus vulgaris & Tendergreen & Fabaceae & Seeds \\
Borecole & Brassica oleracea & Dwarf Green Curled & Brassicaceae & Seeds \\
Cassava & Manihot esculenta & Colombian & Euphorbiaceae & Tissue culture \\
Chard & Beta vulgaris & Rhubarb Red & Amaranthaceae & Seeds \\
Cotton & Gossypium hirsutum & - & Malvaceae & Seeds \\
Mint & Mentha piperita & Peppermint & Lamiaceae & Cuttings \\
Okra & Abelmoschus esculentus & Clemson Spineless & Malvaceae & Seeds \\
Pepper & Capsicum annuum & Californian Wonder & Solanaceae & Seeds \\
Squash & Cucurbita pepo & All Green Bush & Cucurbitaceae & Seeds \\
Sweet potato & Ipomoea batatas & Naspot11 and Beauregard & Convolvulaceae & Cuttings \\
Tobacco & Nicotiana tabacum & Izmir and Basma & Solanaceae & Seeds \\
Tomato & Solanum lycopersicum & Moneymaker & Solanaceae & Seeds \\
\hline
\end{tabular}


Table 2 Summary of B. tabaci samples from which colonies of B. tabaci populations used in this study were established, with associated GenBank accessions of their partial $3^{\prime}$ mtCOI sequences and mitogenomes

\begin{tabular}{|c|c|c|c|c|c|c|}
\hline Country & Species & Group & Plant & Year & GenBank ( $\left.3^{\prime} \mathrm{mtCOI}\right)$ & GenBank (mitogenome) \\
\hline Spain & MED & Q1 & Melon & 2013 & MH357339 & MH205752 $2^{\mathrm{a}}$ \\
\hline Sudan & MED & Q1 & Cotton & 1978 & MH357340 & MH714535 \\
\hline Israel & MED & Q2 & Cotton & 2003 & MH357341 & MH205753 ${ }^{\mathrm{a}}$ \\
\hline Uganda & "ASL" & ASL & Okra & 2013 & MH357342 & MH205754 ${ }^{\mathrm{a}}$ \\
\hline
\end{tabular}

${ }^{a}$ Vyskočilová et al. (2018)

${ }^{\mathrm{b}}$ This study

(657 bp) used for B. tabaci identification (Frohlich et al. 1999; Dinsdale et al. 2010; Mugerwa et al. 2018), as described in Vyskočilová et al. (2018). In brief, genomic DNA was extracted using the Chelex method (Walsh et al. 1991) and PCR of the 3' partial mtCOI sequence was performed with primers 2195Bt and COI2-BtSh2 (Mugerwa et al. 2018) at $52{ }^{\circ} \mathrm{C}$ annealing temperature and Sanger sequenced (Source Bioscience, Nottingham, UK). The sequences trimmed to $657 \mathrm{bp}$ were compared with (1) consensus sequences for 24 putative species of $\mathrm{B}$. tabaci (Dinsdale et al. 2010) to verify the MED putative species and (2) MED mtCOI haplotypes (Gueguen et al. 2010) to place our populations in a recognised naming framework. The sequence analyses and nucleotide divergence calculations were carried out in Geneious, version 10.0.8 (Kearse et al. 2012). The Sanger-sequenced data were checked for errors and pseudogenes as described in Vyskočilová et al. (2018). The GenBank accession numbers for partial mtCOI sequences are given in Table 2 .

The presence of the primary bacterial endosymbiont (Portiera) and five secondary endosymbionts (Arsenophonus, Cardinium, Hamiltonella, Rickettsia and Wolbachia) in Spain Q1, Israel Q2 and Uganda "ASL" was reported in Vyskočilová et al. (2018). In this study, we have added the Sudan Q1 population, which was screened in the same way as the others. Briefly, a conventional PCR with genusspecific primers (Ghosh et al. 2015) was performed using genomic DNA from ten individual females per each colony as a template. Positive and negative controls were included in screening for each endosymbiont. PCR products were visualised by agarose gel electrophoresis, with results summarised in Table S1 in Online Resource 1.

\section{Mitogenome nucleotide sequence divergences}

Mitogenomes of Spain Q1, Israel Q2 and Uganda "ASL" were accessed from GenBank (accession numbers in Table 2). The mitogenome of Sudan Q1 was generated in addition, using the protocol detailed in Vyskočilová et al. (2018). In brief, genomic DNA from a single male was used to generate the library for high-throughput sequencing on the
Illumina HiSeq 4000 platform (Novogene Bioinformatics Institute, China). The mitogenome was assembled by mapping reads to the reference MED mitogenome JQ906700 (Wang et al. 2013) and annotated in MITOS2 (Bernt et al. 2013). Concatenations of 15 genes (13 protein-coding and two rRNA genes) with total length of 12,595 bp were used to calculate the pairwise nucleotide differences ( $p$ distance) among the four populations in Geneious 10.0.8 (Kearse et al. 2012).

\section{Oviposition and leaf preference assay}

All plants from Table 1 except mint were used for the oviposition assay. Three to six experimental replicates were used for each combination of plant and whitefly population. Each plant had only three leaves in different stages: (1) "mature", the first true leaf, (2) "young", the last fully expanded leaf and (3) "immature", the youngest, not fully expanded leaf. Other leaves were carefully removed with sharp scissors $\geq 24 \mathrm{~h}$ prior to the release of whitefly adults. The exceptions were bean and chard, in which only two leaves of similar age were used, and hence were excluded from the leaf age preference assay.

Whitefly adults used in the experiments were collected from a synchronised colony. For each population, aubergine plants carrying large numbers of nymphs were taken from the core colony, devoid of all adults, and put in a separate cage. After 24-48 h, adults that have emerged on these plants ("young adults" hereafter) were collected into glass tubes $(0.5 \mathrm{~cm}$ in diameter, $6.0 \mathrm{~cm}$ long) and their sex was determined using a stereomicroscope. Thirty young adults (15 males and 15 females) were released onto each experimental plant, except for cotton, okra and pepper, onto which 50 adults (25 males and 25 females) were released. The parental adults were removed from the plant $48 \mathrm{~h}$ after release. The eggs laid on the abaxial leaf side were counted using a stereomicroscope, and a photograph of the leaf was taken. The oviposition rate was then expressed as the number of eggs laid per female in $48 \mathrm{~h}$.

To determine the oviposition preference for leaves of different ages, numbers of eggs/female/48 $\mathrm{h}$ were further 
divided by the leaf surface area. The areas were calculated based on the leaf photographs using the online tool SketchAndCalc (Dobbs 2011; available at www.sketc handcalc.com) (Table S2 in Online Resource 1). The eggs/ female $/ 48 \mathrm{~h} / \mathrm{cm}^{2}$ values were multiplied by an appropriate number assigned to the leaf stage (mature $=1$, young $=2$, immature $=3$ ) and summed. Leaf preference scores were calculated for each plant by dividing the sum of eggs/ female $/ 48 \mathrm{~h} / \mathrm{cm}^{2}$ values by the sum of eggs/female/48 $\mathrm{h} /$ $\mathrm{cm}^{2} \times$ leaf stage number.

\section{Survival, fecundity and sex ratio assay}

Data on adult survival, progeny counts and progeny sex ratio were recorded from a separate set of plants from the oviposition assay. All plants from Table 1 were used, with three to seven replicates for each combination of plant and whitefly population. Experimental plants that had grown vigorously had one or two leaves removed $\geq 24 \mathrm{~h}$ before the whitefly release to enable them to fit inside the experimental cage. Thirty young adults ( 15 females and 15 males) from a synchronised colony (detailed above) were released onto each experimental plant. The numbers of surviving adults were monitored during the period of 16-19 days, after which the parental generation was collected to avoid interference with the count of the $F_{1}$ generation. Adults of the $F_{1}$ generation from all replicates were collected at three time points of 21 , 28 and 35 days post-release. The collected $F_{1}$ adults were frozen at $-20{ }^{\circ} \mathrm{C}$ in order to be counted, and their sex was determined later. The total cumulative count of $F_{1}$ adults from each replicate was used for the analysis of progeny counts and sex ratio.

\section{Statistical analyses}

The statistical analyses and plots were done in R ( R Development Core Team 2011; www.R-project.org). Whitefly performance on different plant hosts was analysed at four levels: (1) female oviposition rate, (2) adult whitefly survival, (3) $F_{1}$ progeny counts and (4) proportion of females in the $\mathrm{F}_{1}$ progeny.

The counts of eggs and $F_{1}$ adults were analysed by a generalised linear model with a negative binomial error distribution and a log link using the MASS library (Venables and Ripley 2002). The estimated mean survival times were computed by survival analysis with censoring. The data file contained information on time of death in days for each whitefly (denoted by " 1 ") in each replicate from day 1 to day 16-19; the whiteflies surviving beyond that period were censored (denoted by " 0 "). The survival regression model was fitted by survreg assuming a Weibull distribution. The survival curves were plotted using the survfit function. For the proportion of $F_{1}$ female progeny, a generalised linear model with binomial error distribution and logit link of the proportional data was used.

Multiple comparisons were performed by Tukey's test (Tukey 1949) using the multcomp package (Hothorn et al. 2008), and significant differences were demonstrated by compact letter display. Comparisons of egg counts, progeny counts, survival times and female proportions between whitefly populations were conducted for each host individually, except for oviposition preference for different leaf stages in which all plants were included in one comparison. $\mathrm{P}$-values from multiple comparisons are given in Tables S3-S6 in the Supplementary Material.

\section{Classifying plants as whitefly hosts}

We classified the 13 plants into four categories based on their suitability as a reproductive host for each whitefly population. The categories were delineated based on gaps in distribution of progeny counts, identified by plotting the mean progeny counts in a histogram in $\mathrm{R}(\mathrm{R}$ Development Core Team 2011). Differences between the ranges of favourable plants among whitefly populations were visualised by a Venn diagram.

\section{Results}

\section{Sequence divergence in mitochondrial genes}

The sequence divergences among populations in this study were calculated for the 3' partial mtCOI gene sequence used in whitefly barcoding (Frohlich et al. 1999; Dinsdale et al. 2010; Mugerwa et al. 2018) and for a concatenation of 15 mitochondrial genes (Table 3). The genetically closest populations were Spain Q1 and Sudan Q1 with divergence below $0.5 \%$ in both regions, followed by Spain Q1 and Israel Q2

Table 3 Nucleotide sequence divergence within the 3' barcoding region of mtCOI gene (657 bp) and across 15 mitochondrial genes $(12,595 \mathrm{bp})$

\begin{tabular}{lllll}
\hline & Spain Q1 & Sudan Q1 & Israel Q2 & Uganda "ASL" \\
\hline 3' mtCOI & & & & \\
Spain Q1 & - & & & \\
Sudan Q1 & 0.15 & - & & \\
Israel Q2 & 0.91 & 1.07 & - & \\
Uganda "ASL" & 2.59 & 2.74 & 1.98 & - \\
15 genes & & & & \\
Spain Q1 & - & & & \\
Sudan Q1 & 0.45 & - & & \\
Israel Q2 & 1.06 & 1.17 & - & \\
Uganda "ASL" & 3.93 & 4.00 & 3.91 & - \\
\hline
\end{tabular}


that were about $1 \%$ divergent. Uganda "ASL" was genetically distant from the three MED populations, the least from Israel Q2 (1.98-3.91\%) and the most from Sudan Q1 (2.74-4\%) in $3^{\prime} \mathrm{mtCOI}$ and 15 mitochondrial genes, respectively.

\section{Oviposition rate}

The oviposition rate was expressed as the number of eggs laid by one female in $48 \mathrm{~h}$. Significant differences $(P<0.05)$ between populations occurred on 6 out of 12 plants: bean, cassava, cotton, okra, pepper and tomato (Fig. 1 and Table S3 in Online Resource 1).

The biggest differences among populations occurred on cassava, bean, okra and cotton. Israel Q2 females laid 20 times more eggs than Uganda "ASL" females on cassava
$(P<0.01)$. Spain Q1 and Uganda "ASL" females laid, respectively, $3.3(P<0.05)$ and $3.9(P<0.01)$ times more eggs than Israel Q2 females on bean. On okra, Uganda "ASL" females laid 2.6-2.8 times more eggs $(P<0.01)$ compared with females from the three MED populations. Another marked difference occurred on cotton where Spain Q1 females laid 2.6 times more eggs than Israel Q2 $(P<0.05)$.

Collectively for all four populations, the highest numbers of eggs were laid on sweet potato, aubergine and bean (Table 4). The lowest numbers of eggs occurred on chard, cassava and tobacco.

The mean oviposition rate from all plants revealed that Uganda "ASL" and Spain Q1 females were more fertile than Sudan Q1 and Israel Q2 females. The highest mean
Fig. 1 Oviposition rates of females from four whitefly populations on 12 host plants. Box length represents the interquartile range, whiskers express the full range, and black bar corresponds to the median. Different letters above the boxes indicate significant differences between whitefly populations on each plant individually (Tukey's test, $P<0.05$ )
Table 4 Oviposition rates (eggs/ female/48 h) \pm standard errors and number of replicates $(n)$ of four whitefly populations on 12 host plants

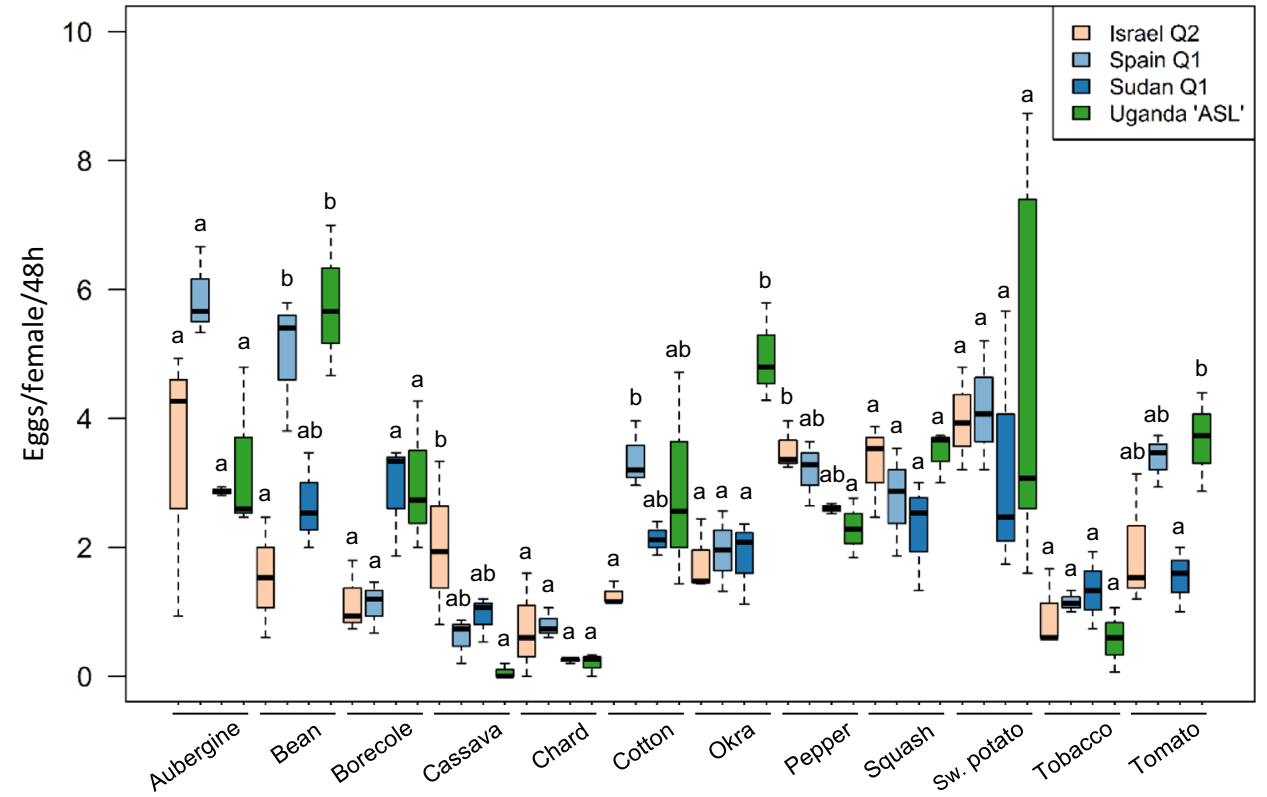

\begin{tabular}{lcccccccc}
\hline & Israel Q2 & $(n)$ & Spain Q1 & $(n)$ & Sudan Q1 & $(n)$ & Uganda “ASL" & $(n)$ \\
\hline Aubergine & $3.4 \pm 1.1$ & $(3)$ & $5.9 \pm 1.4$ & $(3)$ & $2.9 \pm 1.0$ & $(3)$ & $3.3 \pm 1.0$ & $(3)$ \\
Bean & $1.5 \pm 0.7$ & $(3)$ & $5.0 \pm 1.3$ & $(3)$ & $2.7 \pm 0.9$ & $(3)$ & $5.8 \pm 1.4$ & $(3)$ \\
Borecole & $1.2 \pm 0.6$ & $(3)$ & $1.1 \pm 0.6$ & $(3)$ & $2.9 \pm 1.0$ & $(3)$ & $3.0 \pm 1.0$ & $(3)$ \\
Cassava & $2.0 \pm 0.8$ & $(3)$ & $0.6 \pm 0.4$ & $(3)$ & $0.9 \pm 0.6$ & $(3)$ & $0.1 \pm 0.1$ & $(3)$ \\
Chard & $0.7 \pm 0.5$ & $(3)$ & $0.8 \pm 0.5$ & $(3)$ & $0.2 \pm 0.3$ & $(3)$ & $0.2 \pm 0.3$ & $(3)$ \\
Cotton & $1.3 \pm 0.6$ & $(3)$ & $3.4 \pm 1.1$ & $(3)$ & $2.1 \pm 0.8$ & $(3)$ & $2.9 \pm 1.0$ & $(3)$ \\
Okra & $1.8 \pm 0.8$ & $(3)$ & $1.9 \pm 0.8$ & $(3)$ & $1.9 \pm 0.8$ & $(3)$ & $5.0 \pm 1.3$ & $(3)$ \\
Pepper & $3.5 \pm 1.1$ & $(3)$ & $3.2 \pm 1.0$ & $(3)$ & $2.6 \pm 0.9$ & $(3)$ & $2.3 \pm 0.9$ & $(3)$ \\
Squash & $3.3 \pm 1.0$ & $(3)$ & $2.8 \pm 1.0$ & $(3)$ & $2.3 \pm 0.9$ & $(3)$ & $3.5 \pm 1.1$ & $(3)$ \\
Sweet potato & $4.0 \pm 1.2$ & $(3)$ & $4.2 \pm 1.2$ & $(3)$ & $3.3 \pm 1.0$ & $(3)$ & $4.4 \pm 0.9$ & $(6)$ \\
Tobacco & $1.0 \pm 0.6$ & $(3)$ & $1.2 \pm 0.6$ & $(3)$ & $1.3 \pm 0.7$ & $(3)$ & $0.6 \pm 0.4$ & $(3)$ \\
Tomato & $2.0 \pm 0.8$ & $(3)$ & $3.4 \pm 1.1$ & $(3)$ & $1.5 \pm 0.7$ & $(3)$ & $3.7 \pm 1.1$ & $(3)$ \\
Mean & $2.1 \pm 0.3$ & & $2.8 \pm 0.3$ & & $2.1 \pm 0.2$ & & $3.0 \pm 0.3$ & \\
\hline
\end{tabular}


fertility was achieved by Spain Q1 on aubergine and bean, and Uganda "ASL" on bean and okra (Table 4). Raw data can be accessed from Online Resource 2.

The comparison of egg distribution between mature, young and immature leaves revealed differences in female oviposition preferences between hosts (Fig. 2). On tobacco and tomato, the preference to oviposit on older leaves was significantly higher $(P<0.05)$ than on all other plants. In contrast, young leaves were strongly preferred on sweet potato and pepper. The leaf preference did not differ significantly among the whitefly populations $(P>0.5)$.

\section{Adult survival times and curves}

The average survival times were estimated in the survival analysis as the number of days from release on the plant to death of an individual. Significant differences $(P<0.05)$ between populations occurred on all 13 plants (Fig. 3 and Table S4 in Online Resource 1).

For all populations, the highest adult survival occurred on sweet potato, cotton and aubergine. The shortest adult survival times were observed on cassava, chard and tomato. Spain Q1 and Israel Q2 lived longer on average across all plants, compared with Sudan Q1 and Uganda "ASL" (Table 5). Despite the low mean survival times across plants, Uganda "ASL" adults feeding on sweet potato reached an exceptionally high estimated life span of $47.4 \pm 8.6$ days.

Fig. 2 Plant scores representing female oviposition preference for leaves of different ages (mature $=1$, young $=2$, immature $=3$ ). Box length represents the interquartile range, whiskers express the full range, and black bar corresponds to the median. Different letters above the boxes indicate significant differences between plants (Tukey's test, $P<0.05)$
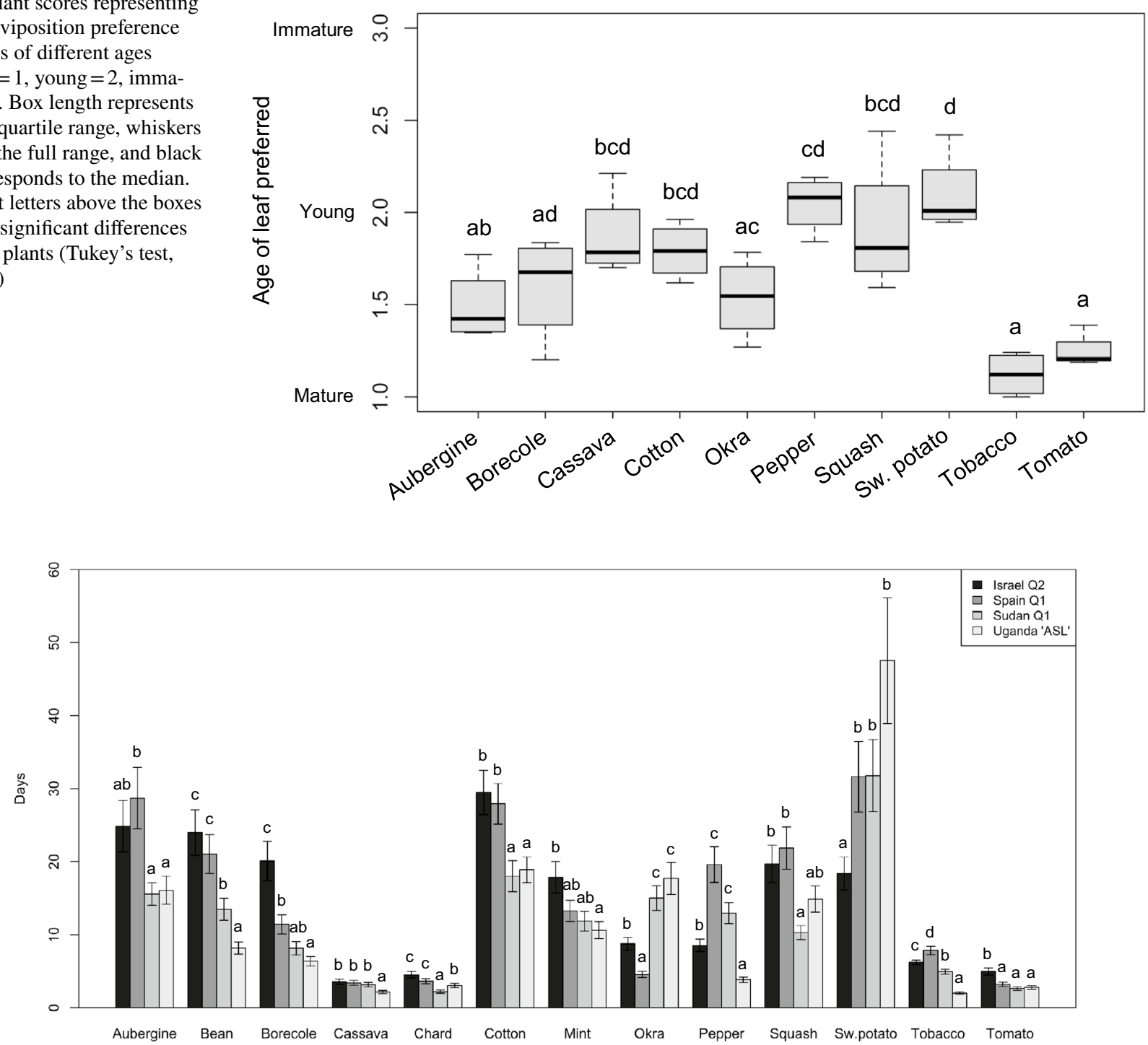

Fig. 3 Mean adult survival times of the four whitefly populations on 13 host plants, calculated in the survival analysis. Different letters above the error bars indicate significant differences between whitefly populations on each plant individually (Tukey's test, $P<0.05$ ) 
Table 5 Adult survival times (days) \pm standard errors and number of replicates $(n)$ for four whitefly populations on 13 host plants

\begin{tabular}{lrlrlrlrl}
\hline & Israel Q2 & $(n)$ & \multicolumn{1}{c}{ Spain Q1 } & $(n)$ & Sudan Q1 & $(n)$ & Uganda “ASL” & $(n)$ \\
\hline Aubergine & $24.8 \pm 3.5$ & $(3)$ & $28.7 \pm 4.2$ & $(3)$ & $15.6 \pm 1.6$ & $(5)$ & $16.1 \pm 1.9$ & $(3)$ \\
Bean & $24.0 \pm 3.5$ & $(3)$ & $21.0 \pm 2.7$ & $(3)$ & $13.5 \pm 1.5$ & $(3)$ & $8.2 \pm 0.8$ & $(3)$ \\
Borecole & $20.1 \pm 2.7$ & $(3)$ & $11.4 \pm 1.3$ & $(3)$ & $8.2 \pm 0.9$ & $(3)$ & $6.4 \pm 0.7$ & $(3)$ \\
Cassava & $3.6 \pm 0.3$ & $(3)$ & $3.4 \pm 0.3$ & $(3)$ & $3.2 \pm 0.3$ & $(3)$ & $2.2 \pm 0.2$ & $(3)$ \\
Chard & $3.6 \pm 0.4$ & $(3)$ & $3.6 \pm 0.3$ & $(3)$ & $2.2 \pm 0.2$ & $(3)$ & $3.1 \pm 0.3$ & $(3)$ \\
Cotton & $29.5 \pm 3.0$ & $(6)$ & $27.9 \pm 2.8$ & $(6)$ & $18.0 \pm 2.1$ & $(3)$ & $18.9 \pm 1.8$ & $(5)$ \\
Mint & $17.8 \pm 2.2$ & $(3)$ & $13.3 \pm 1.5$ & $(3)$ & $11.8 \pm 1.3$ & $(3)$ & $10.6 \pm 1.1$ & $(3)$ \\
Okra & $8.8 \pm 0.9$ & $(3)$ & $4.6 \pm 0.4$ & $(3)$ & $15.0 \pm 1.7$ & $(3)$ & $17.7 \pm 2.2$ & $(3)$ \\
Pepper & $8.6 \pm 0.9$ & $(3)$ & $19.6 \pm 2.5$ & $(3)$ & $12.9 \pm 1.4$ & $(3)$ & $3.8 \pm 0.4$ & $(3)$ \\
Squash & $19.7 \pm 2.6$ & $(3)$ & $21.8 \pm 2.9$ & $(3)$ & $10.3 \pm 0.9$ & $(5)$ & $14.9 \pm 1.8$ & $(3)$ \\
Sweet potato & $18.4 \pm 2.3$ & $(3)$ & $31.6 \pm 4.8$ & $(3)$ & $31.7 \pm 4.9$ & $(3)$ & $47.4 \pm 8.6$ & $(3)$ \\
Tobacco & $6.2 \pm 0.3$ & $(7)$ & $7.9 \pm 0.6$ & $(6)$ & $4.9 \pm 0.3$ & $(6)$ & $2.0 \pm 0.2$ & $(3)$ \\
Tomato & $5.0 \pm 0.5$ & $(3)$ & $3.2 \pm 0.3$ & $(3)$ & $2.6 \pm 0.2$ & $(3)$ & $2.8 \pm 0.3$ & $(3)$ \\
Mean & $11.3 \pm 0.4$ & & $12.9 \pm 0.5$ & & $9.6 \pm 0.3$ & & $9.2 \pm 0.3$ & \\
\hline
\end{tabular}

Relatively long survival times (about 32 days) on sweet potato were also observed for Spain Q1 and Sudan Q1. A similar life span (28-30 days) was observed for Israel Q2 on cotton and Spain Q1 on aubergine and cotton. Raw data can be accessed from Online Resource 2.

The dynamics of a population's decline on each plant species was demonstrated by survival curves (Fig. 4). The initial death rate was the fastest on tomato and cassava, on which population sizes dropped to or below $50 \%$ within 2.5 and 3.3 days on average, respectively. On tobacco and chard, the population decline to $50 \%$ occurred after 4 days on average. The continued death rate was the fastest on cassava, chard and tomato, on which the populations declined to or below $10 \%$ in $4.3,5.5$ and 8.6 days, respectively.

The patterns of adult survival differed between Uganda "ASL" and other three populations. For example, the "ASL" population on tobacco dropped to $10 \%$ within two days, while for other populations the same decline took 13 or more days. Similarly, on pepper the "ASL" population declined by two-thirds within two days, while the same decline took 11 or more days for Q1 and Q2 populations. Bean was favourable for the survival of all Q1 and Q2 populations, but "ASL" population dropped below 50\% within three days. In contrast, about $40 \%$ of "ASL" population survived for 18 days on okra, but for the other three populations only 0-10\% survived the same conditions.

Plants favourable for adult survival of all four populations were cotton, aubergine and sweet potato.

\section{$F_{1}$ progeny counts}

The progeny counts were expressed as a cumulative sum of emerged adults per replicate up to day 35 after the parental release. Significant differences $(P<0.05)$ between whitefly groups occurred on 10 out of 13 plants (Fig. 5 and
Table S5 in Online Resource 1). The three exceptions were cassava, chard and tomato, on which either no, or only a single, $F_{1}$ adult emerged for all populations (Table 6).

The most significant differences among populations occurred on okra, bean, pepper and squash. Okra was an exceptionally suitable host for Uganda "ASL", as its progeny was significantly larger than that of Israel Q2 (29.9-fold, $P<0.001$ ) and Sudan Q1 (3.7-fold, $P<0.05)$. Spain Q1 failed to produce any offspring on okra, but was the most successful population on bean, producing 56.3 times more progeny than Uganda "ASL" $(P<0.001)$ and 2.9 times more than Sudan Q1 (non-significant). Israel Q2 failed to develop on bean. Pepper was only suitable for Q1 populations. Squash was very favourable for Uganda "ASL", progeny of which was 65.4 and 13.6 times more than Israel Q2 and Sudan Q1, respectively $(P<0.001$ and $P<0.05$, respectively). The hosts suitable for reproduction of all four populations were sweet potato, cotton and aubergine.

The largest numbers of progeny across populations were produced on aubergine, cotton, sweet potato and okra (Table 6). In addition to cassava and chard, on which no adults were produced, the lowest number of $F_{1}$ adults emerged on tomato, tobacco and pepper.

Uganda "ASL" was the most fecund population on average (Table 6), but also displayed the most dramatic differences between plants. It failed to produce offspring on five host plants (cassava, chard, pepper, tobacco and tomato) and on further three plants (bean, mint and borecole) produced only a few offspring. Spain Q1 and Sudan Q1 had more consistent and moderately high fecundity rates. Israel Q2 was appreciably less fecund in comparison with the other three populations (2.5-fold less than Uganda "ASL" and about twofold less than Spain and Sudan Q1). Raw data can be accessed from Online Resource 2. 

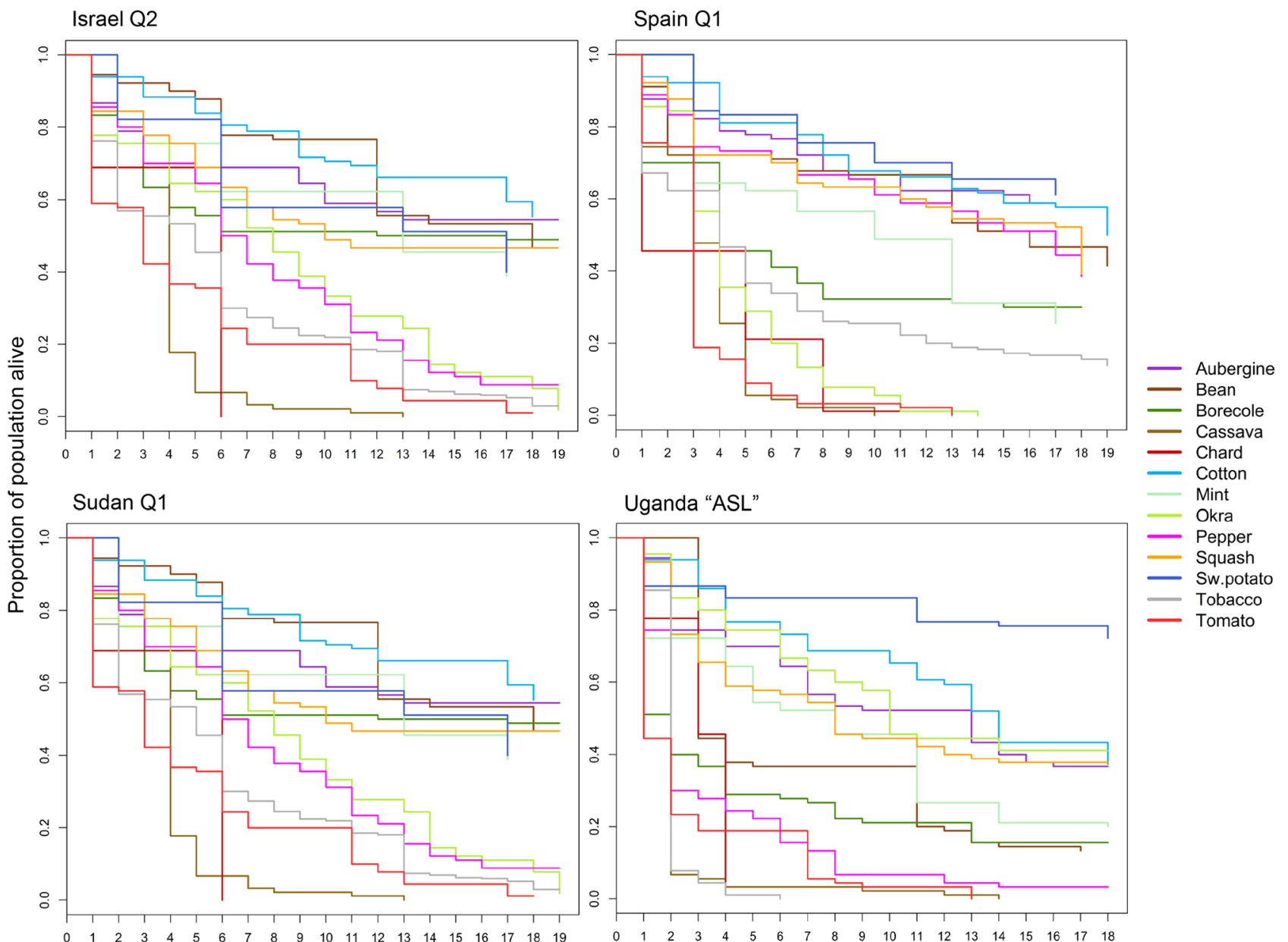

Days after release

Fig. 4 Survival curves showing whitefly population survival dynamics on 13 host plants over a period of 16-19 days post-release, generated from raw data

Fig. 5 Numbers of $F_{1}$ adults in progeny produced by four whitefly populations on 13 host plants. Box length represents the interquartile range, whiskers express the full range, and black bar corresponds to the median. Different letters above the boxes indicate significant differences between whitefly populations on each plant individually (Tukey's test, $P<0.05$ )

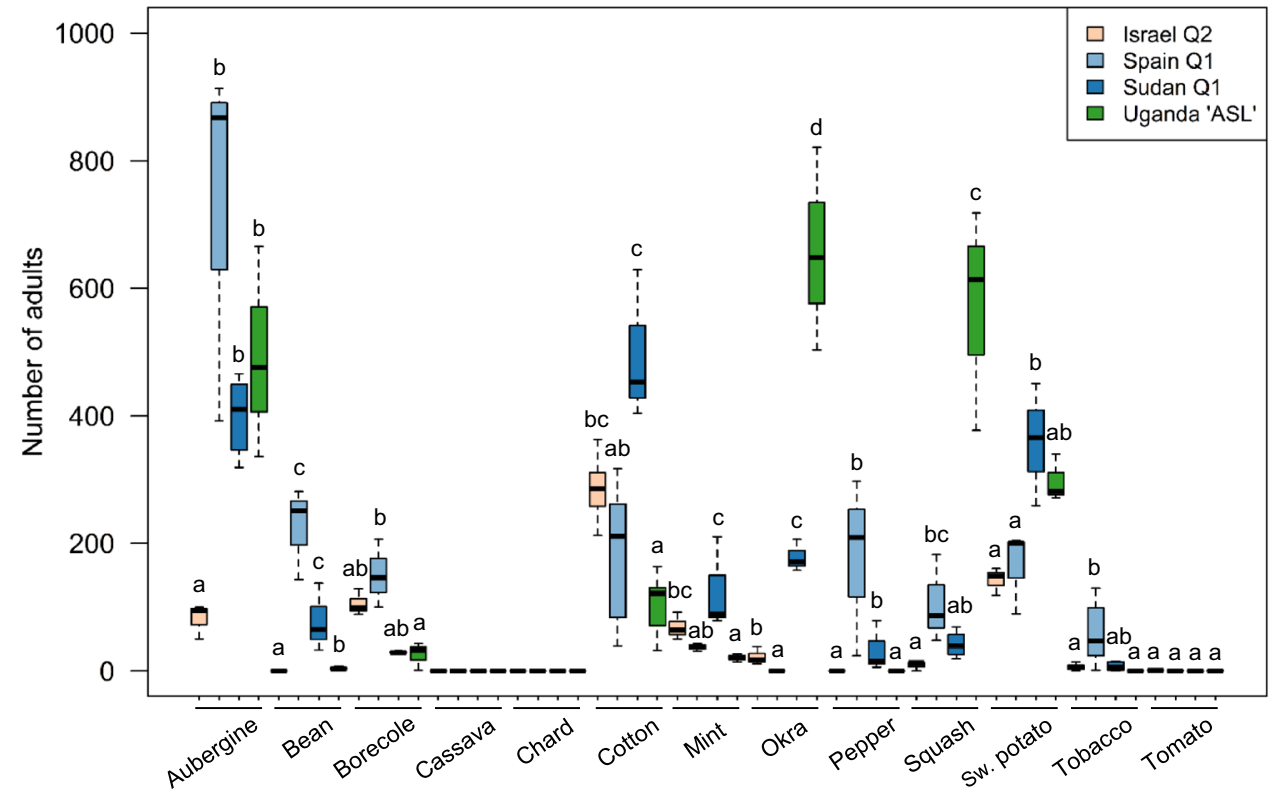


Table $6 \mathrm{~F}_{1}$ progeny counts \pm standard errors and number of replicates $(n)$ for four whitefly populations on 13 host plants

\begin{tabular}{lcccccccc}
\hline & Israel Q2 & $(n)$ & Spain Q1 & $(n)$ & Sudan Q1 & $(n)$ & Uganda “ASL” & $(n)$ \\
\hline Aubergine & $81.7 \pm 23.7$ & $(3)$ & $724.0 \pm 205.3$ & $(3)$ & $398.4 \pm 87.7$ & $(5)$ & $492.3 \pm 139.8$ & $(3)$ \\
Bean & $0.0 \pm 0.0$ & $(3)$ & $225.0 \pm 64.2$ & $(3)$ & $78.3 \pm 22.7$ & $(3)$ & $4.0 \pm 1.6$ & $(3)$ \\
Borecole & $105.3 \pm 30.4$ & $(3)$ & $150.7 \pm 43.2$ & $(3)$ & $29.7 \pm 9.0$ & $(3)$ & $25.7 \pm 7.8$ & $(3)$ \\
Cassava & $0.0 \pm 0.0$ & $(3)$ & $0.0 \pm 0.0$ & $(3)$ & $0.0 \pm 0.0$ & $(3)$ & $0.0 \pm 0.0$ & $(3)$ \\
Chard & $0.0 \pm 0.0$ & $(3)$ & $0.0 \pm 0.0$ & $(3)$ & $0.0 \pm 0.0$ & $(3)$ & $0.0 \pm 0.0$ & $(3)$ \\
Cotton & $285.8 \pm 57.6$ & $(6)$ & $187.2 \pm 37.8$ & $(6)$ & $495.3 \pm 140.7$ & $(3)$ & $103.6 \pm 23.1$ & $(5)$ \\
Mint & $68.7 \pm 20.0$ & $(3)$ & $37.3 \pm 11.1$ & $(3)$ & $126.0 \pm 36.2$ & $(3)$ & $20.7 \pm 6.4$ & $(3)$ \\
Okra & $22.0 \pm 6.8$ & $(3)$ & $0.0 \pm 0.0$ & $(3)$ & $178.0 \pm 50.9$ & $(3)$ & $657.3 \pm 186.5$ & $(3)$ \\
Pepper & $0.0 \pm 0.0$ & $(3)$ & $176.7 \pm 50.5$ & $(3)$ & $33.3 \pm 10.0$ & $(3)$ & $0.0 \pm 0.0$ & $(3)$ \\
Squash & $8.7 \pm 3.0$ & $(3)$ & $105.7 \pm 30.5$ & $(3)$ & $41.8 \pm 10.7$ & $(5)$ & $569.3 \pm 161.6$ & $(3)$ \\
Sweet potato & $142.3 \pm 40.8$ & $(3)$ & $164.7 \pm 47.2$ & $(3)$ & $358.7 \pm 102.0$ & $(3)$ & $297.7 \pm 84.8$ & $(3)$ \\
Tobacco & $6.1 \pm 1.5$ & $(7)$ & $57.8 \pm 12.0$ & $(6)$ & $7.0 \pm 1.8$ & $(6)$ & $0.0 \pm 0.0$ & $(3)$ \\
Tomato & $1.0 \pm 0.6$ & $(3)$ & $0.3 \pm 0.3$ & $(3)$ & $0.0 \pm 0.0$ & $(3)$ & $0.3 \pm 0.3$ & $(3)$ \\
Mean & $66.2 \pm 20.2$ & & $138.3 \pm 42.7$ & & $135.5 \pm 41.8$ & & $163.9 \pm 53$ & \\
\hline
\end{tabular}

\section{Proportion of females in $F_{1}$ progeny}

Significant differences $(P<0.05)$ in the proportion of female progeny between whitefly groups occurred on 5 out of 13 plants: aubergine, cotton, mint, pepper and sweet potato (Fig. 6 and Table S6 in Online Resource 1).

The largest differences in proportion of female $\mathrm{F}_{1}$ progeny occurred on cotton (30.3 percentage points between Sudan Q1 and Uganda "ASL") and pepper (29.4 percentage points between Spain Q1 and Sudan Q1) (Table 7) and were both statistically significant $(P<0.001)$. In general, we observed the highest percentage of females on bean and aubergine, while the lowest occurred on mint and sweet potato.

The mean proportion of females produced by the four populations ranged from $33.16 \%$ (Spain Q1) to $51.0 \%$ (Sudan Q1). Raw data can be accessed from Online Resource 2.

\section{Classification of host plants}

The histogram plotting frequencies of mean progeny counts (Fig. 7a) revealed four clusters: (1) 0, (2) 1-10, (3) 20-85 and (4) more than $100 \mathrm{~F}_{1}$ adults. Based on these values, we classified the plants into four categories expressing the level of suitability as whitefly reproductive hosts: (1) unsuitable, (2) partially suitable, (3) suitable and (4) favourable. The full list of plants categorised for each population is summarised in Fig. $7 b$.

Comparing the ranges of favourable reproductive hosts among the four populations (Fig. 7c) revealed that Spain Q1 had the largest host range with seven favourable hosts out of the 13 tested plants. In contrast, this number is five for Sudan Q1 and Uganda "ASL", and only three for Israel Q2. Hosts favourable for all populations were cotton and sweet potato; aubergine was favourable for all but Israel Q2.
Fig. 6 Percentages of female adults in $\mathrm{F}_{1}$ progeny produced by four whitefly populations on 10 host plants. Cassava, chard and tomato are not shown due to the absence of $F_{1}$ generation in all four populations. Box length represents the interquartile range, whiskers express the full range, black bar corresponds to the median, and circles represent outliers. Different letters above the boxes indicate significant differences between whitefly populations on each plant individually (Tukey's test, $P<0.05)$

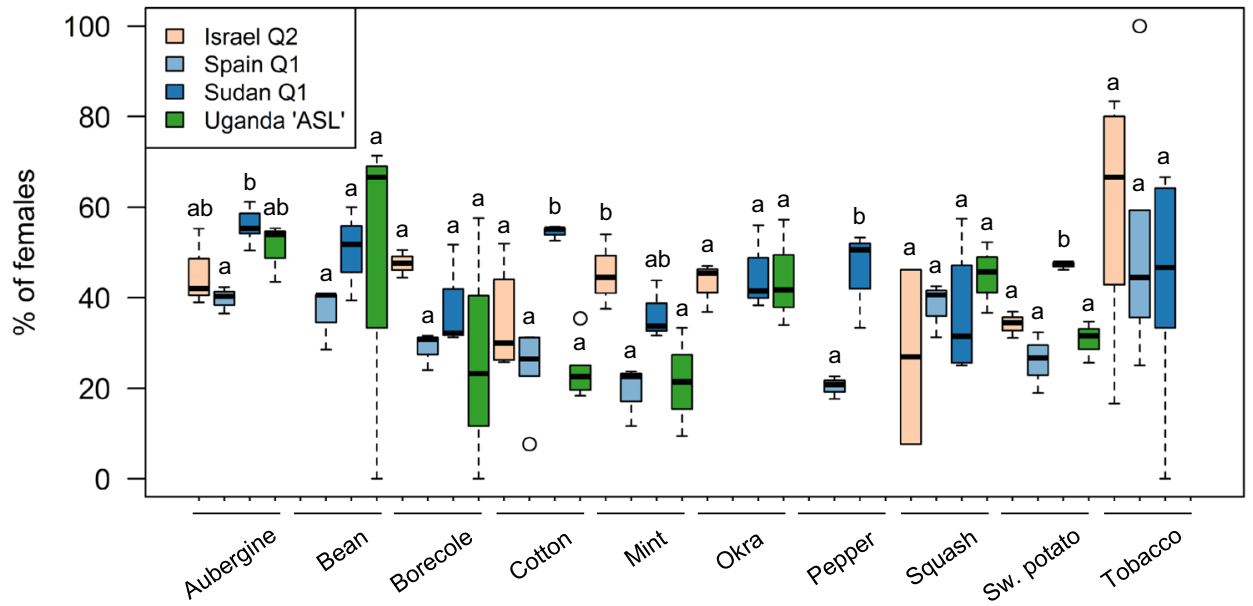


Table 7 Percentages of $\mathrm{F}_{1}$ female progeny \pm standard errors and number of replicates (n) for four whitefly populations on 10 host plants. Cassava, chard and tomato are not shown due to the absence of $F_{1}$ generation for all populations, and dashes indicate the absence of $F_{1}$ generation for some populations on the remaining plants

\begin{tabular}{lllllllll}
\hline & Israel Q2 & $(n)$ & Spain Q1 & $(n)$ & Sudan Q1 & $(n)$ & Uganda “ASL” & $(n)$ \\
\hline Aubergine & $45.5 \pm 3.2$ & $(3)$ & $39.2 \pm 1.0$ & $(3)$ & $56.3 \pm 1.1$ & $(5)$ & $52.2 \pm 1.3$ & $(3)$ \\
Bean & - & $(3)$ & $35.6 \pm 1.8$ & $(3)$ & $52.3 \pm 3.3$ & $(3)$ & $58.3 \pm 14.2$ & $(3)$ \\
Borecole & $47.5 \pm 2.8$ & $(3)$ & $29.6 \pm 2.1$ & $(3)$ & $38.2 \pm 5.2$ & $(3)$ & $37.7 \pm 5.5$ & $(3)$ \\
Cotton & $34.9 \pm 1.2$ & $(6)$ & $27.7 \pm 1.3$ & $(6)$ & $54.2 \pm 1.3$ & $(3)$ & $23.9 \pm 1.9$ & $(5)$ \\
Mint & $44.7 \pm 3.5$ & $(3)$ & $18.8 \pm 3.7$ & $(3)$ & $38.9 \pm 2.5$ & $(3)$ & $22.6 \pm 5.3$ & $(3)$ \\
Okra & $40.9 \pm 6.1$ & $(3)$ & - & $(3)$ & - & $(3)$ & $45.6 \pm 1.1$ & $(3)$ \\
Pepper & - & $(3)$ & - & $(3)$ & $50 \pm 5.0$ & $(3)$ & - & $(3)$ \\
Squash & $26.9 \pm 0.1$ & $(3)$ & $39.7 \pm 2.7$ & $(3)$ & $35.9 \pm 3.7$ & $(5)$ & $43.3 \pm 1.2$ & $(3)$ \\
Sweet potato & $34.2 \pm 2.3$ & $(3)$ & $25.9 \pm 2.0$ & $(3)$ & $47.2 \pm 1.5$ & $(3)$ & $30.2 \pm 1.5$ & $(3)$ \\
Tobacco & $55.8 \pm 0.1$ & $(7)$ & $41.5 \pm 2.6$ & $(6)$ & $50.0 \pm 7.7$ & $(6)$ & - & \\
Mean & $37.9 \pm 0.9$ & & $33.16 \pm 0.6$ & & $51.0 \pm 0.6$ & & $42.5 \pm 0.6$ & \\
\hline
\end{tabular}

Three hosts were not suitable for any population: cassava, chard and tomato.

\section{Discussion}

We have shown significant differences in host range between MED and "ASL" species, providing biological evidence of their distinctness in addition to their reproductive incompatibility and genetic divergence (Vyskočilová et al. 2018). Furthermore, significant differences also occurred between populations of the Q1 and Q2 mitochondrial groups and even within the $\mathrm{Q} 1$ group. We measured a number of life history traits for each population on each host to see how the parameters relate to each other and which could be useful for making decisions in pest management.

\section{Differences in host ranges among the MED populations and "ASL" species}

For the purpose of comparing host plant ranges among MED and "ASL" populations, the $\mathrm{F}_{1}$ progeny counts were identified as the most informative for assessing the host suitability. The rationale behind this decision was twofold: (1) the oviposition rate does not fully capture reproductive success on a host without data on the survival of the later developmental stages up to adulthood and (2) adult survival is a proxy for adult feeding success, but does not capture the performance of immature stages developing on the host. It is the pest's ability to produce further generations, ultimately, that is the key component of their population dynamics, infestation and spread in the field.

Our host assessment divided the plants into four clusters based on the number of $F_{1}$ adults that successfully completed their life cycle on the plant. Data presented in Fig. 7b, c suggest that Spain Q1 was the most polyphagous among the populations studied. The performance of Uganda "ASL" was more polarised than the other populations; it did poorly on many hosts ( $0-25 \mathrm{~F}_{1}$ adults), but on the favourable ones it performed very well (298-657 $\mathrm{F}_{1}$ adults). Israel $\mathrm{Q} 2$, on the other hand, was the only population that did not outperform other populations on any plant. This result could be due to a mismatch between the assayed plants and the actual range of favourable plants for Israel Q2, or an overall lower fecundity of this population, as indicated by the low mean fecundity (Table 6).

The Sudan Q1 population provided a model for comparison of how genetic relatedness and geographic proximity of whitefly populations relate to their host plant ranges. At the mitochondrial DNA level, Sudan Q1 was the most closely related to Spain Q1 and the least close to Uganda "ASL". Geographically, however, it was the opposite. Comparing the host use of these three populations, Spain Q1 and Sudan Q1 shared similar preferences for bean, pepper and squash. However, on borecole, okra and sweet potato, the preferences of Sudan Q1 resembled more closely those of Uganda "ASL". In addition, differences in biological adaptations are further evident in that Sudan Q1 outperformed all other populations on cotton and mint.

\section{Discrepancies between parental and offspring fitness}

Our results not only allowed a comparison between whitefly groups, but also allowed a comparison between the parental fitness (oviposition rate and survival) and the fitness of their immature offspring (progeny counts). According to the optimal oviposition theory, the oviposition preference of the female should correlate with host suitability for offspring development (Jaenike 1978). However, this correlation in published studies ranges from excellent to poor (Mayhew 1997; Scheirs 2002). An alternative theory is the optimal foraging model which predicts that adults prefer to feed on those hosts that give the highest adult performance, which takes the form of realised fecundity (Stephens and Krebs 1986; Scheirs et al. 2000). For the B. tabaci species 

plants' suitability for the four $B$. tabaci populations based on the number of $F_{1}$ adults produced. a Histogram showing the distribution of mean $\mathrm{F}_{1}$ progeny counts of all populations on all plants with four identified clusters i-iv. b Host plants ranked in descending order of suitability for each whitefly population, except for plants with zero $F_{1}$ adults that appear in alphabetical order. Colour-coding follows the histogram above. c Distribution of favourable hosts (cluster iv) among the four whitefly populations. Plants not shown are cassava, chard and tomato that were unsuitable for all populations, and tobacco that fell into the suitable cluster iii for Spain Q1
Fig. 7 Classification of host

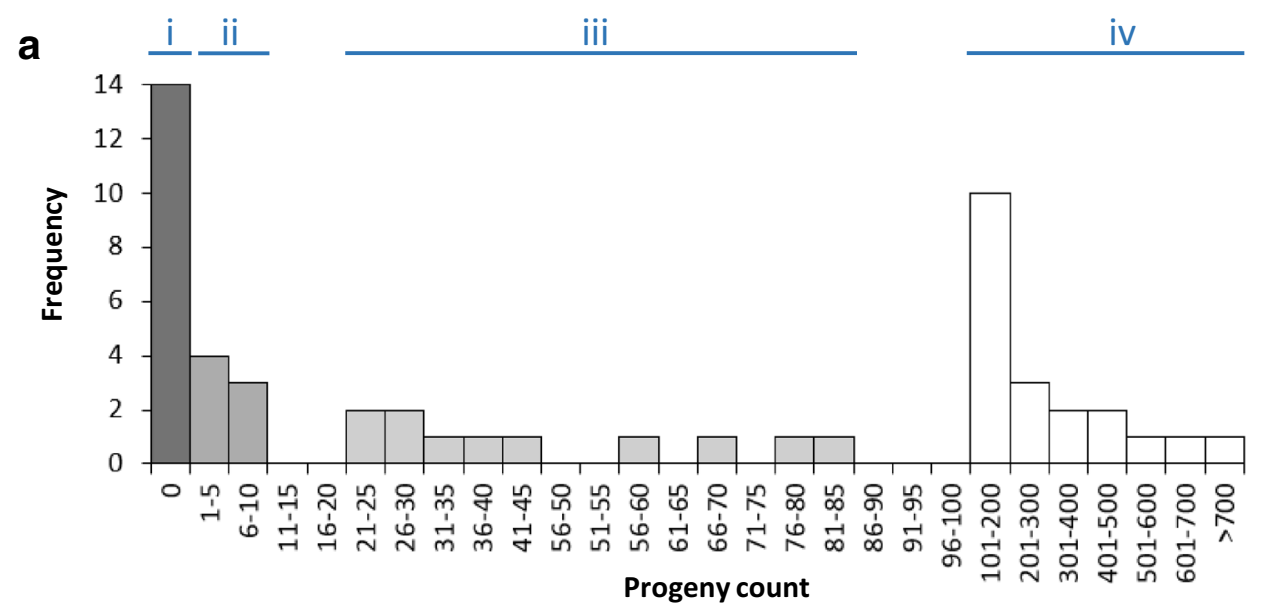

b

\begin{tabular}{ccccc}
\hline Rank & Israel Q2 & Spain Q1 & Sudan Q1 & Uganda “ASL" \\
\hline 1 & cotton & aubergine & cotton & okra \\
2 & sweet potato & bean & aubergine & squash \\
3 & borecole & cotton & sweet potato & aubergine \\
4 & aubergine & pepper & okra & sweet potato \\
5 & mint & sweet potato & mint & cotton \\
6 & okra & borecole & bean & borecole \\
7 & squash & squash & squash & mint \\
8 & tobacco & tobacco & pepper & bean \\
9 & tomato & mint & borecole & tomato \\
10 & bean & tomato & tobacco & cassava \\
11 & cassava & cassava & cassava & chard \\
12 & chard & chard & chard & pepper \\
13 & pepper & okra & tomato & tobacco \\
\hline
\end{tabular}

C

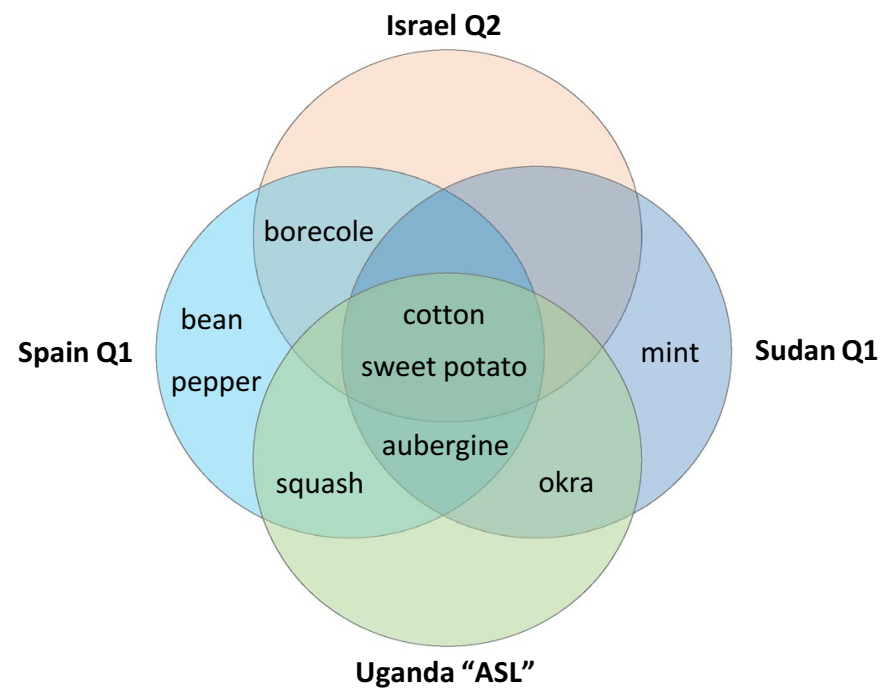

complex, the current evidence does not support the optimal oviposition theory, as they have been shown to lay eggs on nutritionally inferior or unsuitable hosts (Iida et al. 2009; Jiao et al. 2012).

Discrepancies between the oviposition rate and progeny success were also observed in this study. The most striking was that of Uganda "ASL" on bean, where oviposition rate was the second highest among all measurements (Table 4); however, the number of adult offspring was near zero (Table 6). Other examples of such discrepancies included Israel Q2 on pepper and squash, Spain Q1 and Uganda "ASL" on tomato, and Uganda "ASL" and Sudan Q1 on borecole. In most of these examples the adult survival was also poor (Table 5), but with exceptions (e.g. Israel 
Q2 on squash). Conversely, in some cases the number of $\mathrm{F}_{1}$ progeny exceeded the expected number of $\mathrm{F}_{1}$ adults (mean number of eggs/female/48 h multiplied by fifteen and nine, giving an optimistic estimate of progeny counts after 15 females ovipositing for 18 days with no mortality). The largest difference was observed for Israel Q2 and Sudan Q1 on cotton, progeny counts of which were 1.7fold greater than the optimistic estimate. These two cases can be partially explained by the likely underestimation of the oviposition rate measured in the first $48 \mathrm{~h}$.

We also found that the adult survival could not be easily linked to offspring survival, either. For example, Israel Q2 adults survived very well on bean, although the offspring failed to develop. Similar, less extreme examples include Israel Q2 on borecole and Uganda "ASL" and Spain Q1 on sweet potato. An opposite trend, in which the large offspring success was not reflected in good parental survival, was also observed (Sudan Q1 on cotton, Sudan Q1 on mint, Uganda "ASL" on squash).

Our results suggest that there is no straightforward relationship between adult feeding success, female oviposition efforts and the offspring developmental success. There are likely additional factors contributing to the female's decision to oviposit other than the quality of her feed. For example, the leaf surface morphology can play a role (Chu et al. 1995; Mcauslane 1996). Possible explanations include interference with the air movement and capturing humidity by the leaf pubescence (Butler et al. 1986; Inbar and Gerling 2008) and evolutionary changes stemming from multi-trophic interactions between whiteflies, plants and natural enemies (van Lenteren et al. 1995; Guershon and Gerling 1999; Meekes et al. 2000; Queiroz and Oliveira 2001; Head et al. 2004). Therefore, the preference of a female whitefly to oviposit on a particular host could reflect an evolutionary trade-off between host nutritional suitability and the risk of being attacked by natural enemies (Dicke 2000; Murphy 2004; Vosteen et al. 2016).

We did observe a pattern in the oviposition preference for different leaf stages. The strongest oviposition preference for older leaves occurred on tomato, tobacco, aubergine and okra, all of which had relatively smooth old leaves, whereas the young were densely covered with trichomes (Fig. S1 in Online Resource 1). In contrast, five out of six plants on which relatively young leaves were preferred were glabrous (sweet potato, pepper, cassava, cotton and borecole). The only exception was squash, young leaves of which were moderately hairy. We hypothesise that there were additional leaf properties playing a large role in progeny success other than the leaf surface morphology, such as the chemical defence mechanisms of plants against pests (Channarayappa et al. 1992; Fürstenberg-Hägg et al. 2013).

\section{Coping with plant defence mechanisms against herbivores}

The capability of whiteflies to feed and reproduce on a plant requires mechanisms dealing with the plant defences. These include chemical defence by producing allelochemicals or physical barriers in the form of leaf pubescence.

Borecole (and other Brassica spp.) produce glucosinolates which, upon feeding damage, are broken down into bioactive compounds by the enzyme myrosinase (Bones and Rossiter 1996). The ability of Israel Q2 to feed on borecole was expected, because of its reported ability to circumvent this defence mechanism by glucosinolate desulfation (Malka et al. 2016). As all four populations in this study were able to feed and reproduce on borecole (26-151 $\mathrm{F}_{1}$ adults), it is possible that all of them could employ this deactivating mechanism, albeit with varying level of efficiency.

The unsuitability of tomato for all populations was surprising, because tomato is considered a good host for MED (Bonato et al. 2007; Jiao et al. 2012) and the variety "Moneymaker" has previously been shown susceptible to MED in Spain (Nombela et al. 2003; Rodríguez-López et al. 2011). Because the oviposition rate on tomato was relatively high for all four populations (Fig. 1), the adverse effects of the plant defence probably took place during the development of eggs or nymphs. Tomato leaves are covered with eight possible types of glandular and non-glandular trichomes (Channarayappa et al. 1992). The glandular trichomes produce zingiberene and acylsugars that can have a repelling, fumigant or toxic effect to whiteflies, or the released exudates can trap whitefly adults (Kisha 1981; Muigai et al. 2002). The glandular trichomes (type IV) were negatively correlated with whitefly oviposition and density and positively correlated with trapping and mortality (Muigai et al. 2003; Oriani and Vendramim 2010). The tomato trichome density varies between studies, which was attributed to the variation in experimental factors, such as the photoperiod, plant age, fertilisers and the growing environment (greenhouses or the field) (Oriani and Vendramim 2010 and references within). In this study, the experimental conditions with tomato plants confined within a small cage could have potentially influenced the leaf surface morphology that might have negatively impacted on the whitefly survival and oviposition rate on tomato, although this hypothesis remains to be tested.

Tobacco leaves contain nicotine, which is a highly toxic alkaloid for herbivores (Appel and Martin 1992; Steppuhn et al. 2004; du Rand et al. 2015). Tobacco was not a favourable host for any of the populations in this study; however, Spain Q1 was the only population for which tobacco was at least suitable ( $58 \mathrm{~F}_{1}$ adults). This was expected, as the mtCOI of MED Q1 corresponds to the original B. tabaci syntype collected from tobacco in Greece (Gennadius 1889; Tay et al. 2012) and because the invasive MED Q1 
populations were reported to develop resistance to neonicotinoids (Fernández et al. 2009; Luo et al. 2010; Dennehy et al. 2010). Neonicotinoids are pesticides with a similar mode of action to nicotine (Tomizawa and Casida 2003), and so the detoxification mechanisms of these two compounds are likely similar (du Rand et al. 2015; Magesh et al. 2017). In contrast, Sudan Q1 did not reproduce well on tobacco ( $7 \mathrm{~F}_{1}$ adults), despite the close genetic link to the invasive Q1 populations. This was not surprising, because the Sudan Q1 population, also called SUD-S or BTS, has been used frequently as a susceptible control in toxicological studies (Byrne et al. 2000; Nauen et al. 2002; Rauch and Nauen 2003; Nauen and Denholm 2005; Ma et al. 2007). This low ability to detoxify nicotine could partially explain why the sub-Saharan populations are not invasive.

The detoxification capacity could also be affected by the composition of endosymbiotic bacteria. For example, Rickettsia-positive MEAM1 whiteflies were more susceptible to pyriproxyfen, acetamiprid, thiamethoxam and spiromesifen than their Rickettsia-negative counterparts (Kontsedalov et al. 2008). Similarly, the presence of Rickettsia in a double infection with Arsenophonus increased the mortality of MED whiteflies in Israel after treatment with pyriproxyfen, thiamethoxam, spiromesifen and imidacloprid, when compared to MED whiteflies with single Arsenophonus infection (Ghanim and Kontsedalov 2009). Interestingly, the most polyphagous Spain Q1 was the only population in which Rickettsia was not detected by the PCR screening in our study. However, the endosymbiont abundance was not tested in this study and further investigation is needed to establish the role of endosymbionts in the detoxification mechanisms.

\section{Implications for pest control}

The polyphagy and ability to detoxify nicotine could serve as a prerequisite to the invasiveness of Spain Q1 and related populations. Polyphagy makes pests more flexible and challenging to control, while the nicotine detoxification capacity makes them predisposed to develop resistance to neonicotinoid pesticides. Fighting the invasive MED, therefore, requires an alternative and combined approach.

Our findings could contribute to making decisions about plant choices in cultural practices. For example, intercropping with plants supporting long adult survival and development of large numbers of offspring, such as sweet potato, cotton and aubergine, could have detrimental effects to adjacent susceptible crops. Such plants would support the multiplication and facilitate the spread of MED or "ASL" populations in the field. More suitable plants for intercropping would be those attractive for feeding and oviposition, but toxic for adults or nymphs, such as bean for Uganda "ASL" or pepper and squash for Israel Q2. However, an experiment with choice conditions would be needed to ascertain whether there is a preference for the trap crop over the susceptible crop. In addition, it would be useful to study the relationships between intercropping plants and whitefly natural enemies, as a positive relationship can enhance the overall efficiency of pest control (Landis et al. 2000).

Plants unattractive or toxic for whiteflies could be used as a physical barrier around susceptible crops. For example, it has been suggested to use maize as a barrier crop to protect cotton fields from MED whiteflies in China, because $B$. tabaci do not attack maize (Zhang et al. 2014). Our results suggest that chard could serve as a barrier crop against MED, but the low height of these plants needs to be taken into consideration. Cassava was similarly unsuitable for MED as chard; however, its use as a barrier crop would be impossible in sub-Saharan Africa, because multiple African $B$. tabaci species colonise and seriously damage cassava (Macfadyen et al. 2018).

Our data could also be used to design comparative transcriptomic studies for understanding the molecular mechanisms conferring the whiteflies' ability to utilise host plants. Such data could help in identifying targets for RNA interference and developing whitefly-resistant crop varieties or trap crops with a whitefly-specific lethal factor. For example, a whitefly-resistant transgenic tobacco was developed by inserting a dsRNA precursor for RNA interference specifically designed to silence the vital insect gene for vacuolar ATPase enzyme, subunit A (Thakur et al. 2014).

\section{Experimental limitations and recommendations}

The existing literature on whitefly host performance often describes meticulous studies of whitefly development from egg to adult on leaf discs or in clip-cages (e.g. Xu et al. 2011; Shah and Liu 2013; Alon et al. 2013; Pappas et al. 2018). In contrast, our experimental approach was possibly closer to field conditions, as the released adult whiteflies were allowed to feed and oviposit anywhere on the plant. However, we acknowledge that our methods have a number of limitations.

Counting eggs from the whole plant was more time-consuming than from leaf discs/clip-cages, and the leaf areas were not equal across replicates. In addition, measuring of the oviposition rate during the first $48 \mathrm{~h}$ after release might not be representative of the rate throughout the female's life span, partly because of the adjustment time needed after being handled by a researcher and forced into a host shift. In addition, despite allowing a $\geq 24$-h recovery period, the stress response caused by leaf removal might have affected the oviposition and/or egg hatching (Ament et al. 2004; De Puysseleyr et al. 2011).

The adult survival data in our study served as a proxy of adult feeding success and provided an indication about the host's potential to support the survival of adult 
whitefly populations in the field. The method adopted in this study, however, might be too time-consuming for a practical application, as it required nearly daily counting for almost three weeks. The monitoring period could be shortened; however, it should be noted that the dynamics of a population decline can differ between the periods directly after the host shift and after settling on the host.

The $F_{1}$ progeny counts were the most easily obtainable, as they only required releasing parental adults with a standardised sex ratio and counting their progeny; periodic monitoring was not essential. This method could be modified to be more time efficient by shortening the ovipositing period and not recording the offspring sex ratios, as these were not as significantly different nor indicative of the reproductive success.

We would like to note that the offspring sex ratio might have been affected by secondary endosymbiotic bacteria, namely Wolbachia, Cardinium or Rickettsia, which can manipulate the reproductive system of their insect hosts (Perlman et al. 2006; Engelstädter and Hurst 2009). This could be the reason behind the female-biased offspring of Sudan Q1 (Table 7), which was fixed for both Rickettsia and Wolbachia, or male-biased offspring of Spain Q1, which did not contain any of the three reported reproductive manipulators (Table S1).

An overall limitation of this study is that only one population was tested from each locality on only one or two varieties per plant. Ideally, several related populations would be tested on multiple plant varieties in more replicates in order to make a better assessment of host suitability (Iida et al. 2009).

\section{Conclusions}

We have provided additional biological evidence of the distinctness of MED and "ASL" species and showed that close genetic relationships within $B$. tabaci, specifically as illustrated by the MED species, do not equal the same host range. Our findings have implications for chemical and cultural aspects of integrated pest management. Our data on the whitefly performance on various hosts could contribute to decision-making for intercropping, trap crops or crop rotation. We advise against the use of neonicotinoid pesticides for the control of invasive MED B. tabaci, given its ability to detoxify nicotine. Future work will include research aimed at understanding the molecular mechanisms behind the whitefly-plant interactions and identifying targets for development of whiteflyresistant plants.

\section{Author contributions}

SV, SS and JC conceived the research and contributed ideas. SV conducted experiments, analysed the data and wrote the manuscript. All authors read and approved the manuscript.

Acknowledgements We acknowledge the financial support of SV's $\mathrm{PhD}$ scholarship and research by University of Greenwich (Vice-Chancellor's Scholarship, VCS-ES-08-14-2) and The Bill \& Melinda Gates Foundation (African Cassava Whitefly Project, OPP1058938). We thank Jesús Navas-Castillo, Shai Morin, Habibu Mugerwa and Rothamsted Research for providing whitefly colonies, Sharon van Brunschot for the help in generating the Illumina HiSeq data, Stephen Young for the help with statistical analyses and Rebecca Grimsley, Natalie Morley and Quentin Bédrune for assistance with laboratory work. We are also grateful to Wee Tek Tay, Sandy Williams and Jacqueline St. Quinton for their help in improving the manuscript.

\section{Compliance with ethical standards}

Conflict of Interest The authors declare that they have no conflict of interest.

Ethical approval All applicable international, national and/or institutional guidelines for the care and use of animals were followed. This article does not contain any studies with human participants performed by any of the authors.

Open Access This article is distributed under the terms of the Creative Commons Attribution 4.0 International License (http://creativeco mmons.org/licenses/by/4.0/), which permits unrestricted use, distribution, and reproduction in any medium, provided you give appropriate credit to the original author(s) and the source, provide a link to the Creative Commons license, and indicate if changes were made.

\section{References}

Alon M, Malka O, Eakteiman G et al (2013) Activation of the phenylpropanoid pathway in Nicotiana tabacum improves the performance of the whitefly Bemisia tabaci via reduced jasmonate signaling. PLoS ONE 8:e76619

Ament K, Kant MR, Sabelis MW et al (2004) Jasmonic acid is a key regulator of spider mite-induced volatile terpenoid and methyl salicylate emission in tomato. Plant Physiol 135:2025-2037

Appel HM, Martin MM (1992) Significance of metabolic load in the evolution of host specificity of Manduca sexta. Ecology 73:216-228

Baldwin IT, Preston CA (1999) The eco-physiological complexity of plant responses to insect herbivores. Planta 208:137-145

Bedford ID, Briddon RW, Markham PG et al (1992) Bemisia tabaci - biotype characterisation and the threat of this whitefly species to agriculture. In: Proceedings of Brighton crop protection conference pests and diseases, pp 1235-1240

Bernt M, Donath A, Jühling F et al (2013) MITOS: improved de novo metazoan mitochondrial genome annotation. Mol Phylogenet Evol 69:313-319

Bird J (1957) A whitefly-transmitted mosaic of Jatropha gossypifolia, 22nd edn. Agricultural Experiment Station, University of Puerto Rico, San Juan 
Bird J, Maramorosch K (1978) Viruses and virus diseases associated with whiteflies. In: Lauffer MA, Bang FB, Maramorosch K, Smith KM (eds) Advances in virus research. Academic Press, London, pp 55-110

Bonato O, Lurette A, Vidal C, Fargues J (2007) Modelling temperature-dependent bionomics of Bemisia tabaci (Q-biotype). Physiol Entomol 32:50-55

Bones AM, Rossiter JT (1996) The myrosinase-glucosinolate system, its organisation and biochemistry. Physiol Plant 97:194-208

Boykin LM, Armstrong KF, Kubatko L, De Barro PJ (2012) Species delimitation and global biosecurity. Evol Bioinforma Online $8: 1-37$

Burban C, Fishpool LDC, Fauquet C et al (1992) Host-associated biotypes within West African populations of the whitefly Bemisia tabaci (Genn.), (Hom., Aleyrodidae). J Appl Entomol 113:416-423

Butler GD, Henneberry TJ, Wilson FD (1986) Bemisia tabaci (Homoptera: Aleyrodidae) on cotton: adult activity and cultivar oviposition preference. J Econ Entomol 79:350-354

Byrne FJ, Gorman KJ, Cahill M et al (2000) The role of B-type esterases in conferring insecticide resistance in the tobacco whitefly, Bemisia tabaci (Genn). Pest Manag Sci 56:867-874

Channarayappa C, Shivashankar G, Muniyappa V, Frist RH (1992) Resistance of Lycopersicon species to Bemisia tabaci, a tomato leaf curl virus vector. Can J Bot 70:2184-2192

Chu CC, Henneberry TJ, Cohen AC (1995) Bemisia argentifolii (Homoptera: Aleyrodidae): host preference and factors affecting oviposition and feeding site preference. Environ Entomol 24:354-360

Chu D, Tao YL, Zhang YJ et al (2012) Effects of host, temperature and relative humidity on competitive displacement of two invasive Bemisia tabaci biotypes [Q and B]. Insect Sci 19:595-603

Colvin J, Chowda-Reddy RV, Rekha AR, et al (2004) Ecological and reproductive isolation amongst African and Asian Bemisia tabaci populations. In: Proceedings of the 2nd European whitefly symposium. Cavtat, Croatia, $\mathrm{p} 12$

Costa HS, Brown JK (1991) Variation in biological characteristics and esterase patterns among populations of Bemisia tabaci, and the association of one population with silverleaf symptom induction. Entomol Exp Appl 61:211-219

De Barro PJ, Liu SS, Boykin LM, Dinsdale AB (2011) Bemisia tabaci: a statement of species status. Annu Rev Entomol 56:1-19

De Puysseleyr V, Höfte M, De Clercq P (2011) Ovipositing Orius laevigatus increase tomato resistance against Frankliniella occidentalis feeding by inducing the wound response. ArthropodPlant Interact 5:71-80

Dennehy TJ, Degain BA, Harpold VS et al (2010) Extraordinary resistance to insecticides reveals exotic Q biotype of Bemisia tabaci in the New World. J Econ Entomol 103:2174-2186

Dicke M (2000) Chemical ecology of host-plant selection by herbivorous arthropods: a multitrophic perspective. Biochem Syst Ecol 28:601-617

Dinsdale A, Cook L, Riginos C et al (2010) Refined global analysis of Bemisia tabaci (Hemiptera: Sternorrhyncha: Aleyrodoidea: Aleyrodidae) mitochondrial cytochrome oxidase 1 to identify species level genetic boundaries. Ann Entomol Soc Am 103:196-208

Dobbs EM (2011) SketchAndCalc http://www.SketchAndCalc.com. Accessed 8 March 2018

du Rand EE, Smit S, Beukes M et al (2015) Detoxification mechanisms of honey bees (Apis mellifera) resulting in tolerance of dietary nicotine. Sci Rep 5:11779

Duron O, Bouchon D, Boutin S et al (2008) The diversity of reproductive parasites among arthropods: Wolbachia do not walk alone. BMC Biol 6:27
Elsayed G (2011) Plant secondary substances and insects behaviour. Arch Phytopathol Plant Prot 44:1534-1549

Engelstädter J, Hurst GDD (2009) The ecology and evolution of microbes that manipulate host reproduction. Annu Rev Ecol Evol Syst 40:127-149

Fernández E, Grávalos C, Haro PJ et al (2009) Insecticide resistance status of Bemisia tabaci Q-biotype in south-eastern Spain. Pest Manag Sci 65:885-891

Frohlich DR, Torres-Jerez I, Bedford ID et al (1999) A phylogeographical analysis of the Bemisia tabaci species complex based on mitochondrial DNA markers. Mol Ecol 8:1683-1691

Fürstenberg-Hägg J, Zagrobelny M, Bak S (2013) Plant defense against insect herbivores. Int J Mol Sci 14:10242-10297

Gennadius P (1889) Disease of tobacco plantations in the Trikonia. The aleurodid of tobacco. Ellenike Ga 5:1-3

Ghanim M, Kontsedalov S (2009) Susceptibility to insecticides in the Q biotype of Bemisia tabaci is correlated with bacterial symbiont densities. Pest Manag Sci 65:939-942

Ghosh S, Bouvaine S, Maruthi MN (2015) Prevalence and genetic diversity of endosymbiotic bacteria infecting cassava whiteflies in Africa. BMC Microbiol 15:93

Greathead AH (1986) Host plants. In: Cock MJW (ed) Bemisia tabaci-a literature survey on the cotton whitefly with an annotated bibliography. C.A.B International Institute of Biological Control, Silwood Park, pp 17-26

Gueguen G, Vavre F, Gnankiné O et al (2010) Endosymbiont metacommunities, mtDNA diversity and the evolution of the Bemisia tabaci (Hemiptera: Aleyrodidae) species complex. Mol Ecol 19:4365-4376

Guershon M, Gerling D (1999) Predatory behavior of Delphastus pusillus in relation to the phenotypic plasticity of Bemisia tabaci nymphs. Entomol Exp Appl 92:239-248

Head J, Lawrence AJ, Walters KFA (2004) Efficacy of the entomopathogenic nematode, Steinernema feltiae, against Bemisia tabaci in relation to plant species. J Appl Entomol 128:543-547

Himler AG, Adachi-Hagimori T, Bergen JE et al (2011) Rapid spread of a bacterial symbiont in an invasive whitefly is driven by fitness benefits and female bias. Science 332:254-256

Hothorn T, Bretz F, Westfall P (2008) Simultaneous inference in general parametric models. Biom J 50:346-363

Iida H, Kitamura T, Honda KI (2009) Comparison of egg-hatching rate, survival rate and development time of the immature stage between B- and Q-biotypes of Bemisia tabaci (Gennadius) (Homoptera: Aleyrodidae) on various agricultural crops. Appl Entomol Zool 44:267-273

Inbar M, Gerling D (2008) Plant-mediated interactions between whiteflies, herbivores, and natural enemies. Annu Rev Entomol 53:431-448

Jaenike J (1978) On optimal oviposition behavior in phytophagous insects. Theor Popul Biol 14:350-356

Jiang YX, Lei H, Collar JL et al (1999) Probing and feeding behavior of two distinct biotypes of Bemisia tabaci (Homoptera: Aleyrodidae) on tomato plants. J Econ Entomol 92:357-366

Jiao X, Xie W, Wang S et al (2012) Host preference and nymph performance of B and Q putative species of Bemisia tabaci on three host plants. J Pest Sci 85:423-430

Jiao XG, Xie W, Wang SL et al (2013) Differences in host selection and performance between B and Q putative species of Bemisia tabaci on three host plants. Entomol Exp Appl 147:1-8

Kearse M, Moir R, Wilson A et al (2012) Geneious basic: an integrated and extendable desktop software platform for the organization and analysis of sequence data. Bioinforma Oxf Engl 28:1647-1649 
Kisha JSA (1981) Observations on the trapping of the whitefly Bemisia tabaci by glandular hairs on tomato leaves. Ann Appl Biol 97:123-127

Kontsedalov S, Zchori-Fein E, Chiel E et al (2008) The presence of Rickettsia is associated with increased susceptibility of Bemisia tabaci (Homoptera: Aleyrodidae) to insecticides. Pest Manag Sci 64:789-792

Landis DA, Wratten SD, Gurr GM (2000) Habitat management to conserve natural enemies of arthropod pests in agriculture. Annu Rev Entomol 45:175-201

Liu B, Yan F, Chu D et al (2012a) Difference in feeding behaviors of two invasive whiteflies on host plants with different suitability: implication for competitive displacement. Int J Biol Sci 8:697-706

Liu SS, Colvin J, De Barro PJ (2012b) Species concepts as applied to the whitefly Bemisia tabaci systematics: How many species are there? J Integr Agric 11:176-186

Luo C, Jones CM, Devine G et al (2010) Insecticide resistance in Bemisia tabaci biotype Q (Hemiptera: Aleyrodidae) from China. Crop Prot 29:429-434

Ma D, Gorman K, Devine G et al (2007) The biotype and insecticideresistance status of whiteflies, Bemisia tabaci (Hemiptera: Aleyrodidae), invading cropping systems in Xinjiang Uygur Autonomous Region, northwestern China. Crop Prot 26:612-617

Macfadyen S, Paull C, Boykin LM et al (2018) Cassava whitefly, Bemisia tabaci (Gennadius) (Hemiptera: Aleyrodidae) in East African farming landscapes: a review of the factors determining abundance. Bull Entomol Res 108:565-582

Magesh V, Zhu Z, Tang T et al (2017) Toxicity of neonicotinoids to honey bees and detoxification mechanism in honey bees. IOSR J Environ Sci Toxicol Food Technol 11:102-110

Malka O, Shekhov A, Reichelt M et al (2016) Glucosinolate desulfation by the phloem-feeding insect Bemisia tabaci. J Chem Ecol 42:230-235

Maruthi MN, Colvin J, Thwaites RM et al (2004) Reproductive incompatibility and cytochrome oxidase I gene sequence variability amongst host-adapted and geographically separate Bemisia tabaci populations (Hemiptera: Aleyrodidae). Syst Entomol 29:560-568

Mayhew PJ (1997) Adaptive patterns of host-plant selection by phytophagous insects. Oikos 79:417-428

Mcauslane HJ (1996) Influence of leaf pubescence on ovipositional preference of Bemisia argentifolii (Homoptera: Aleyrodidae) on soybean. Environ Entomol 25:834-841

Meekes ETM, van Voorst S, Joosten NN et al (2000) Persistence of the fungal whitefly pathogen, Aschersonia aleyrodis, on three different plant species. Mycol Res 104:1234-1240

Mound LA, Halsey SH (1978) Whitefly of the world. British Museum (Natural History), London

Mouton L, Gnankiné O, Henri H et al (2015) Detection of genetically isolated entities within the Mediterranean species of Bemisia tabaci: new insights into the systematics of this worldwide pest. Pest Manag Sci 71:452-458

Mugerwa H, Seal SE, Wang HL et al (2018) African ancestry of New World. Bemisia tabaci-whitefly species. Sci Rep 8:2734

Mugerwa H, Rey MEC, Tairo F et al (2019) Two sub-Saharan Africa 1 populations of Bemisia tabaci exhibit distinct biological differences in fecundity and survivorship on cassava. Crop Prot 117:7-14

Muigai SG, Schuster DJ, Snyder JC et al (2002) Mechanisms of resistance in Lycopersicon germplasm to the whitefly Bemisia argentifolii. Phytoparasitica 30:347

Muigai SG, Bassett MJ, Schuster DJ, Scott JW (2003) Greenhouse and field screening of wild Lycopersicon germplasm for resistance to the whitefly Bemisia argentifolii. Phytoparasitica 31:27
Muñiz M, Nombela G (1997) Development, oviposition and female longevity of two biotypes of Bemisia tabaci (Homioptera: Aleyrodidae) on three varieties of Capsicum annuum L. IOBCWPRS Bull 20:143-146

Muñiz M, Nombela G (2001) Differential variation in development of the B- and Q-biotypes of Bemisia tabaci (Homoptera: Aleyrodidae) on sweet pepper at constant temperatures. Environ Entomol 30:720-727

Murphy SM (2004) Enemy-free space maintains swallowtail butterfly host shift. Proc Natl Acad Sci 101:18048-18052

Nauen R, Denholm I (2005) Resistance of insect pests to neonicotinoid insecticides: Current status and future prospects. Arch Insect Biochem Physiol 58:200-215

Nauen R, Stumpf N, Elbert A (2002) Toxicological and mechanistic studies on neonicotinoid cross resistance in Q-type Bemisia tabaci (Hemiptera: Aleyrodidae). Pest Manag Sci 58:868-875

Nombela G, Williamson VM, Muñiz M (2003) The root-knot nematode resistance gene $\mathrm{Mi}-1.2$ of tomato is responsible for resistance against the whitefly Bemisia tabaci. Mol Plant-Microbe Interact MPMI 16:645-649

Oliveira MRV, Henneberry TJ, Anderson P (2001) History, current status, and collaborative research projects for Bemisia tabaci. Crop Prot 20:709-723

Oliver KM, Russell JA, Moran NA, Hunter MS (2003) Facultative bacterial symbionts in aphids confer resistance to parasitic wasps. Proc Natl Acad Sci 100:1803-1807

Omondi BA, Sseruwagi P, Obeng-Ofori D et al (2005) Mating interactions between okra and cassava biotypes of Bemisia tabaci (Homoptera: Aleyrodidae) on eggplant. Int J Trop Insect Sci 25:159-167

Oriani MAG, Vendramim JD (2010) Influence of trichomes on attractiveness and ovipositional preference of Bemisia tabaci (Genn.) B biotype (Hemiptera: Aleyrodidae) on tomato genotypes. Neotrop Entomol 39:1002-1007

Pappas ML, Tavlaki G, Triantafyllou A, Broufas G (2018) Omnivoreherbivore interactions: thrips and whiteflies compete via the shared host plant. Sci Rep 8:3996

Parrella G, Nappo AG, Manco E et al (2014) Invasion of the Q2 mitochondrial variant of Mediterranean Bemisia tabaci in southern Italy: possible role of bacterial endosymbionts. Pest Manag Sci 70:1514-1523

Perlman SJ, Hunter MS, Zchori-Fein E (2006) The emerging diversity of Rickettsia. Proc Biol Sci 273:2097-2106

Perring TM, Cooper A, Kazmer DJ (1992) Identification of the poinsettia strain of Bemisia tabaci (Homoptera: Aleyrodidae) on broccoli by electrophoresis. J Econ Entomol 85:1278-1284

Powell G, Tosh CR, Hardie J (2006) Host plant selection by aphids: behavioral, evolutionary, and applied perspectives. Annu Rev Entomol 51:309-330

Queiroz JM, Oliveira PS (2001) Tending ants protect honeydew-producing whiteflies (Homoptera: Aleyrodidae). Environ Entomol 30:295-297

R Development Core Team R (2011) R: a language and environment for statistical computing

Rauch N, Nauen R (2003) Identification of biochemical markers linked to neonicotinoid cross resistance in Bemisia tabaci (Hemiptera: Aleyrodidae). Arch Insect Biochem Physiol 54:165-176

Rodríguez-López MJ, Garzo E, Bonani JP et al (2011) Whitefly resistance traits derived from the wild tomato Solanum pimpinellifolium affect the preference and feeding behavior of Bemisia tabaci and reduce the spread of Tomato yellow leaf curl virus. Phytopathology 101:1191-1201

Russell LM (1957) Synonyms of Bemisia tabaci (Gennadius) (Homoptera, Aleyrodidae). Bull Brooklyn Entomol Soc 52:122-123 
Scheirs J (2002) Integrating optimal foraging and optimal oviposition theory in plant-insect research. Oikos 96:187-191

Scheirs J, De Bruyn L, Verhagen R (2000) Optimization of adult performance determines host choice in a grass miner. Proc R Soc B Biol Sci 267:2065-2069

Seal SE, vanden Bosch F, Jeger MJ (2006) Factors influencing begomovirus evolution and their increasing global significance: implications for sustainable control. Crit Rev Plant Sci 25:23-46

Shah MMR, Liu TX (2013) Feeding experience of Bemisia tabaci (Hemiptera: Aleyrodidae) affects their performance on different host plants. PLoS ONE 8:e77368

Sseruwagi P, Legg JP, Maruthi MN et al (2005) Genetic diversity of Bemisia tabaci (Gennadius) (Hemiptera: Aleyrodidae) populations and presence of the $\mathrm{B}$ biotype and a non-B biotype that can induce silverleaf symptoms in squash, in Uganda. Ann Appl Biol 147:253-265

Stephens DW, Krebs JR (1986) Foraging theory. Princeton University Press, Princeton

Steppuhn A, Gase K, Krock B et al (2004) Nicotine's defensive function in nature. PLoS Biol 2:e217

Su Q, Preisser EL, Zhou XM et al (2015) Manipulation of host quality and defense by a plant virus improves performance of whitefly vectors. J Econ Entomol 108:11-19

Tay WT, Evans GA, Boykin LM, De Barro PJ (2012) Will the real Bemisia tabaci please stand up? PLoS ONE 7:e50550

Thakur N, Upadhyay SK, Verma PC et al (2014) Enhanced whitefly resistance in transgenic tobacco plants expressing double stranded RNA of v-ATPase A gene. PLoS ONE 9:e87235

Tomizawa M, Casida JE (2003) Selective toxicity of neonicotinoids attributable to specificity of insect and mammalian nicotinic receptors. Annu Rev Entomol 48:339-364

Toscano N, Castle S, Henneberry T, Castle N (1998) Persistent silverleaf whitefly exploits desert crop systems. Calif Agric 52:29-33

Tukey JW (1949) Comparing individual means in the analysis of variance. Biometrics 5:99-114

van Lenteren JC, Hua LZ, Kamerman JW, Rumei X (1995) The parasite-host relationship between Encarsia formosa (Hym., Aphelinidae) and Trialeurodes vaporariorum (Hom., Aleyrodidae) XXVI. Leaf hairs reduce the capacity of Encarsia to control greenhouse whitefly on cucumber. J Appl Entomol 119:553-559
Venables WN, Ripley BD (2002) Modern applied statistics with S. Springer, Berlin

Vosteen I, Gershenzon J, Kunert G (2016) Enemy-free space promotes maintenance of host races in an aphid species. Oecologia 181:659-672

Vyskočilová S, Tay WT, van Brunschot S et al (2018) An integrative approach to discovering cryptic species within the Bemisia tabaci whitefly species complex. Sci Rep 8:10886

Walling LL (2000) The myriad plant responses to herbivores. J Plant Growth Regul 19:195-216

Walling LL (2008) Avoiding effective defenses: strategies employed by phloem-feeding insects. Plant Physiol 146:859-866

Walsh PS, Metzger DA, Higuchi R (1991) Chelex 100 as a medium for simple extraction of DNA for PCR-based typing from forensic material. Biotechniques 10:506-513

Wang P, Sun DB, Qiu BL, Liu SS (2011) The presence of six cryptic species of the whitefly Bemisia tabaci complex in China as revealed by crossing experiments. Insect Sci 18:67-77

Wang HL, Yang J, Boykin LM et al (2013) The characteristics and expression profiles of the mitochondrial genome for the Mediterranean species of the Bemisia tabaci complex. BMC Genom $14: 401$

Werren JH, Baldo L, Clark ME (2008) Wolbachia: master manipulators of invertebrate biology. Nat Rev Microbiol 6:741-751

Xu J, De Barro PJ, Liu SS (2010) Reproductive incompatibility among genetic groups of Bemisia tabaci supports the proposition that the whitefly is a cryptic species complex. Bull Entomol Res 100:359-366

Xu J, Lin KK, Liu SS (2011) Performance on different host plants of an alien and an indigenous Bemisia tabaci from China. J Appl Entomol 135:771-779

Zhang XM, Yang NW, Wan FH, Lövei GL (2014) Density and seasonal dynamics of Bemisia tabaci (Gennadius) Mediterranean on common crops and weeds around cotton fields in northern China. J Integr Agric 13:2211-2220

Publisher's Note Springer Nature remains neutral with regard to jurisdictional claims in published maps and institutional affiliations. 